\title{
Toward the Creation of Disaster-Resilient Communities: The Machizukuri Initiative - the 2011 Tōhoku Great East Japan Earthquake and Tsunami
}

Nidam Marcus Siawsh ( $\square$ nidam.marcus@gmail.com )

RMIT University College of Business https://orcid.org/0000-0001-7559-5449

Konrad Peszynski

RMIT University Business: RMIT University College of Business

Huan Vo-Tran

RMIT University College of Business

Leslie Young

RMIT University College of Business

\section{Research Article}

Keywords: Disaster preparedness and response, Japan, earthquake, tsunami, Machizukuri, Disaster Relief

Posted Date: November 30th, 2021

DOI: https://doi.org/10.21203/rs.3.rs-1082006/v1

License: (9) This work is licensed under a Creative Commons Attribution 4.0 International License.

Read Full License 


\section{Abstract}

Community engagement and involvement is an essential component of managing and responding to disasters. In Japan, greater community involvement and increased participation of its citizens has been encouraged through the machizukuri initiative. The machizukuri are local community councils that played a pivotal role in the recovery efforts following the Tōhoku Great East Japan Earthquake and Tsunami (GETET) that devastated much of northern Japan in 2011. However, their role in those efforts is not well understood.

Thus, the aim of this study was to better understand the role and impact of local communities in responding to and recovering from disasters through examining the role of the machizukuri following the GEJET. An exploratory approach was adopted, and semi-structured interviews were undertaken with eight key decision-makers involved in recovery efforts. Key themes were identified including the overwhelming nature of the GEJET for which Japan was unprepared, and while the central government enacted their disaster management plans, responses were slow and failed to address local priorities. To compensate, the local community and machizukuri assisted and successfully united the local community to fill a gap left by the centralized governments' approach. It is an example of an effective bottom-up approach to address a critical issue. However, the efforts were hindered by a lack of coordination between the various government bodies and aid organisations as well as communication failures that prevented a more coherent response. Recommendations were made to assist countries to remediate these shortcomings and respond more effectively to disasters.

\section{Introduction}

A disaster, by definition, is an overwhelming event often involving either natural or unnatural hazards, leading to extensive property damage, livelihood disruptions, and negative socio-economic impacts (Akhtar, Marr \& Garnevska 2012; UNISDR 2016). Disasters rupture perceptions of normality, thereby revealing sometimes hidden or taken-for-granted dimensions of society. In the aftermath of destructive events, having a quick and reliable relief and recovery system ready to implement is important to lessen the potential for harm and loss of human life and property. It is also important to involve local community members to ensure the assistance given and the resources used are relevant to the community's immediate needs.

Understanding the process of disaster relief and the management of local response and relief efforts in a catastrophic event has suffered from limited attention by scholars and professionals in terms of community participation to better alleviate survivors' suffering. At the heart of such participation in such context is a collective action that typically encompasses a wide array of cultural experiences of humanitarian stakeholders. As much effort as can be witnessed during a catastrophic event, little understanding exists regarding how local initiatives influence local disaster relief. 
Japan is a country that is well acquainted with natural disasters due to its location on the Pacific Rim, where there is a great deal of seismic activity and frequent earthquakes. It provides an intriguing case study for studying? disaster response because Japan's emergency management process is considered unique and provides ample examples of effective community management. It emphasises disaster governance that incorporates local authorities and other community actors in a more "on the frontline" approach to disaster response and participatory methods to support decisions and negotiation (Okada, Fang \& Kilgour 2013).

The World Bank emphasises Japan's superiority in several areas of disaster and emergency preparedness and response strategies in natural disasters. Moreover, the local community training, disaster awareness, and preparedness drills are excellent evidence of collective public exercises for the population, attributable to the significant 'disaster culture' that Japan has developed. The country has faced many disasters throughout recent history and has developed a response system that Button, for example, has referred to as a hidden 'cultural gene' (Button 2010). The history of natural disasters and disaster riskreduction has generated a unique 'culture of disaster risk-reduction', and various activities have been handed down through time and become part of the social fabric (JICA 2017).

Seen from this perspective, the Japanese government has implemented numerous initiatives in previous decades aimed at mobilising communities and empowering local actors like the machizukuri [वस्रा]. These councils are a key paradigm in Japanese urban planning beyond simply disaster response. The

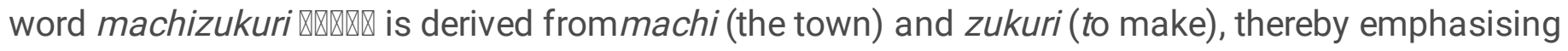
community involvement in urban planning (Cosson 2020; Sorensen \& Funck 2009).

The centrality of the machizukuri brings culture-specific forms of leadership to the forefront in considering the social setting in which disaster recovery occurs. The machizukuri system has a role in Japan as a community organisation system that interacts with other local organisations, such as the disaster-prevention community groups. After the Hanshin-Awaji earthquake disaster in 1995, Kobe's municipal restoration project was designed to promote "community creation by working together".

There is emerging literature on these local Japanese organisations in other post-disaster scenarios as well. The machizukuri has been examined in the post-earthquake response of other natural disasters like the 1995 Great Hanshin-Awaji Earthquake in Kobe (Mavrodieva et al. 2019) Instead of a one-size-fits-all approach that is mechanical and overly technical or devoid of consideration of local politics (McConnell \& Strak 2002) researchers who analyse disaster responses have been calling for more attention to understanding the local relationships between community authorities and other stakeholders in crisis governance. Government resources are limited, and disasters such as earthquakes are unpredictable, and it is challenging for government aid workers to attend to the most immediate humanitarian needs. The capacity to effectively mobilise local resources is also important (Van Wassenhove 2006). Mavrodieva et al. (2019) emphasised the transformative power of the machizukuri because they mobilise local actors and promote the adoption of policies that encourage collective decision-making at the community level. 
This promises the development of more sustainable policies and greater civic engagement in the disaster governance process.

Although the machizukuri are a promising example of civic response, it is still unclear which groups best represent particular civic issues or their legal capacity to take action, which has created some ambiguity (Kaneko 2013). Through these different councils or local entities, community residents develop their interventions for rebuilding after a disaster and regenerating social ties from the ground up. This process is referred to as 'the aid structure' - 'kojo [public help]', 'jijo [self-help]', 'gojo [mutual help in neighborhood]' and 'kyojo [mutual help between unfamiliar persons]', where individual self-reliance is encouraged along with community support (Goulding \& Kiyomiya 2018; Okada, Fang \& Kilgour 2013). At the same time, however, one dimension of local government that was made evident in the GEJET disaster aftermath is the agglomeration of different councils and organisations at the local level. This situation made it difficult for officials to recognise which organisations were responsible for what and to acknowledge other community actors outside the existing framework of community disaster response.

In the context of this research, the notion of a community is referred to as a feel-good factor that establishes common bonds and a sense of belonging among people, interdependence, and mutual commitment that link individuals in a collective unity (Kloos et al. 2012; Manzo \& Perkins 2006; McMillan \& Chavis 1986). Nevertheless, the term has variable meanings (Mills 2004). In particular interest, because it denies those not of a particular community eligibility within its parameters, it is also highly inclusive of those defined as members of it (McMillan \& Chavis 1986).

The present study aimed to better understand the role of local communities in responding to, and facilitating recovery from disasters by examining the role and impact of the machizukuri initiative following the GEJET disaster. Specific aims were to develop a clearer understanding of how local communities can best be involved in disaster recovery efforts including any processes that might facilitate or impede their involvement.

\section{The 2011 Tōhoku Great East Japan Earthquake And Tsunami (Gejet)}

Despite being well prepared to respond to major natural disasters compared to other nations, the scale of the GEJET disaster was unprecedented in Japan. The Tōhoku disaster is one of the most destructive events in the history of global disasters, with the greatest damage being caused by the tsunami (FDMA 2019). An earthquake of magnitude 9.0 struck off the eastern coast of Honshu Island, causing a tsunami $130 \mathrm{~km}$ off the coast of the Miyagi Prefecture. This tsunami inundated over 400 square kilometres of land and washed over the settled coast of north-eastern Japan. The quake and tsunami caused three meltdowns due to a cooling system failure and a hydrogen explosion at the Fukushima Daiichi Nuclear Reactor located on a 3.5 square-kilometre site in the towns of Ōkuma-machi and Futaba-machi in Fukushima Prefecture, northern Japan, which resulted in a level-7 nuclear meltdown and release of radioactive materials (Shibahara 2011). The death toll reached approximately 21,839 from the 
cumulative disaster - and of these, 90 per cent of victims perished due to drowning by the tsunami. In addition, 400,000 houses were fully or partially destroyed, and more than 500,000 residents were evacuated (National Police Agency of Japan 2011).

Figure 2.1 shows how the Iwate Prefecture and neighbouring cities were affected by the 2011 Tohoku Earthquake and the devastating tsunami despite having the world's most advanced tsunami countermeasures. The epicentre is indicated by a red cross on the map below. The Tōhoku region is highlighted in green. The larger seacoast region called the Sanriku Coast is highlighted in blue and covers about $600 \mathrm{~km}$.

The earthquake and the tsunami reached unexpected magnitudes of severity, leaving a trail of devastation behind as entire Japanese communities were obliterated. The total economic damage exceeded 210 billion dollars (not considering the Fukushima nuclear power plant), and is the costliest and most catastrophic natural disaster in world history to date. Major industrial and production activities and exports were halted or decreased due to the damage to stock in the affected areas.

Furthermore, the disaster brought other social challenges to the forefront, especially the inequalities that became evident in rebuilding disaster impacted communities and addressing the aging of a large percentage of the population. These challenges were coupled with profound social changes at the urban level where there was a low birth rate and traditional Japanese values and practices were fading (Muramatsu \& Akiyama 2011).

Table 2.1 Great East Japan Earthquake 2011 Facts

\begin{tabular}{|ll|}
\hline Event Description & Implication \\
\hline Magnitude & M 9.0 \\
\hline Tsunami height & 15 Metres \\
\hline Major damage & $\begin{array}{l}\text { Fukushima Power Plant inundated, causing a partial meltdown and massive } \\
\text { radiation leaks }\end{array}$ \\
\hline Fatalities & 19,846 \\
\hline Injuries/displaced & 368,820 \\
\hline Damage area & 500 Km2 (193 Square Miles) damage to Tōhoku area \\
\hline Damage cost & US\$ 300 Billion \\
\hline Global effects & $\begin{array}{l}\text { Balance of trade impact limited, as area accounts for only 2.5\% of the Japanese } \\
\text { economy }\end{array}$ \\
\hline
\end{tabular}

Disaster Affected Areas - Source: (Kanno 2013) Masao Kanno, "Japanese Transportation Systems after the Great East Japan Earthquake," Consulate of Japan, 2013 
In response to the GEJET, Japan launched a massive relief and recovery response involving all components of Japan's disaster management system (Figures 3.1 and 3.2) including federal and local government organisations, municipal and local councils as well as community organisations and members of the local communities. The involvement of local communities as active participants and key partners in recovery efforts is made explicit in Japan's disaster management protocol (Figure 3) although there is a lack of clarity on how local communities can best be involved in such efforts.

\section{Literature Review: Community-based Disaster Risk Management}

There has been an increasing momentum for governments worldwide to adopt more community-based disaster management programs so that residents in local communities are included in decision-making and planning (Blaikie et al. 2004; Maskrey 1989; Shaw 2014). International organisations have proposed several models that are designed to facilitate implementation of such programs like the Hyogo Framework for Action that outlined action principles for 2005-2015 (Zhou et al. 2017) and the more recent Sendai Framework for Disaster Risk Reduction that provides guiding principles for governments in increasing community engagement in disaster crises through the year 2030. The Sendai Framework emphasises the role of education and the need to address social and material inequalities among the population so that communities become more resilient cumulatively over time and learn to reduce the risk to members in their communities (Trumble 2019). This aim is also embodied in the notion of building back better (BBB) that was taken up as a slogan in many high-profile and large-scale disasters worldwide in recent years, including the 2004 Indian Ocean Tsunami, the 2010 Haiti Earthquake, and the 2011 Great East Japan Earthquake and Tsunami (Mannakkara, Wilkinson \& Potangaroa 2019).

The recovery of the tsunami-stricken regions in Japan has generated the interest of some scholars; however, the focus has largely been on how to reduce risk and create viable engineering or architectural modifications to act as a defence against such disasters (Gokon \& Koshimura 2012; Koshimura \& Shuto 2015; Nagamatsu 2018). Matsuoka et al. (2012) argued that the success of community-based actions in disaster situations relies on the willingness of the community to become involved in disaster management; nevertheless, the links between the community residents and the authorities who govern and allocate resources are also important. The goal is not to have local organisations assume complete autonomy or to face the post-crisis situation in isolation; the point is that community capacities and local knowledge should be acknowledged and put into practice in addressing disasters and response.

In a study conducted by Fitzpatrick and Spialek (2020) in the aftermath of Hurricane Harvey, the researchers looked at how social ties, location, and race influenced every aspect of the ongoing recovery. Primarily, the study emphasised social capital and delineated disparities in community concessions and trust in preparedness, response, and recovery. Fitzpatrick and Spialek (2020) argued that social networks influence peoples' preparedness, response, and recovery capabilities and noted that social capital could exacerbate community inequalities (Aldrich \& Meyer 2015). However, they failed to mention other ways social capital can be problematic in disasters (Fussell et al. 2018). 
Fitzpatrick and Spialek (2020) make an important plea for us to stop making the same disaster mistakes. They suggest a range of community spaces within which disaster planning could take place to ensure whole-community planning is truly inclusive. They maintain that a resident and community-centred approach could create a planning process that better accounts for intersectionality in diversity, vulnerabilities, and capacities in communities (Fitzpatrick \& Spialek 2020). The authors unpack the intersecting and overlapping dimensions of spatial and social disparities and argue these are magnified when natural disasters hit. The authors did more than just recount the individual stories of heartache, destruction, recovery, resiliency, and hope that unfold in the aftermath of a disaster in their study. The stories of resiliency and recovery provide a framework for understanding how space, place and identity shape the collective action and individual experiences of disaster (Fitzpatrick \& Spialek 2020).

Other scholars of disaster studies emphasise the importance of social bonds in post-disaster recovery (Aldrich 2012). Aldrich (2012) suggested that communities play the most important role in all facets of a disaster scenario, and this is true whether government action is relatively efficient or in cases where the government response is inadequate.

Photos of the area are included below.

The World Health Organization concluded that most lives are saved within the first few hours after a disaster with the help of local response teams (WHO 2012). Therefore, the complex issues resulting from a disaster related to restoring livelihoods and ensuring public health are more efficiently addressed if the community is active and well organised. Mavrodieva et al. (2019) discuss how community landowners and small entrepreneurs organised themselves via the machizukuri organisations in the Kobe earthquake in 1995. This network helped victims of the disaster with legal issues and pooling resources. The events and projects the machizukuri organised helped residents cope with the trauma of the disaster by being proactive in their recovery (Mavrodieva et al. 2019). The local organisations were even involved physically in helping to put out fires that resulted from the earthquake and prevent them from spreading. It is important to capture how the machizukuri are brought into action post-disaster in different instances to further enable effectiveness in local disaster response.

\subsection{Overview of the Disaster Management System in Japan}

Japan stands out in the international community in terms of disaster management because it is a country that experiences many natural disasters due to its location on the Pacific Rim, where there is much seismic activity. From the 1950s to the 1990s, Japan has been affected by the Isewan typhoon and Hanshin-Awaji-Daishisai earthquake and other severe disasters. The 2011 GEJET example stands out because it was a triple catastrophe - earthquake, tsunami, and a nuclear event, most significantly revealed strengths and weaknesses. Given that Japan frequently experiences earthquakes and typhoons, Japan prioritises preventing disasters and reducing damage. It has formed a unique and effective emergency management system. 
The Disaster Countermeasures Basic Act (1961) is Japan's legal instrument which lays out a comprehensive and strategic disaster management system. The Act describes the overall framework for preventing and reducing the risk from natural disasters, response and recovery. The Act is the legal foundation for establishing the Central Disaster Management Council, responsible for crucial Cabinet policies (Cabinet Office 2016). The council is chaired by the prime minister, and members include line ministers, semi-public organisations, and representatives from academia (Figure 3.2).

The Act is considered one of the earliest examples of a point shift from response-oriented to preventive approaches to disaster following the Isewan Typhoon (Typhoon Vera) in 1959, which caused serious damage to major urban places in central Japan (Cabinet Office 2016). At that time, Japan was still in reconstruction after WWII, so strengthened its DRR system by investing 5-8\% of the annual budget in DRR projects to build a strong infrastructure and take preventative measures against disasters.

This shift triggered the recognition that government organisations (public assistance) cannot be the only source of help in the event of a disaster. It was also important to save one's own life (self-help) and support each other (mutual support) as part of the local communities' involvement in the relief and recovery operations (Tanaka 2008).

This legislative change also helped to formalise the practice of volunteering and community organisation in the aftermath of a disaster. Examples of similar legislation include the Act for the Promotion of Earthquake-proof Retrofits of Buildings and the Act to Support Livelihood Recovery for disaster Victims that were passed. Since the Great East Japan Earthquake of 2011, Japan has continued to review existing legislation and DRR measures of the risk assessments and countermeasures for major earthquakes and improving DRR measures (JICA 2017). Every time Japan faces a disaster, it revisits existing regulations in order to develop effective programs for disaster mitigation, research how disaster occurs, and develop effective countermeasures against it. Japan has also been at the forefront of DRR technology development (JICA 2017). Figure 3.2 (below) outlines the Disaster Management System in Japan, which provides a comprehensive disaster management system for all phases of a disaster: prevention, mitigation and preparedness, emergency response, and recovery and rehabilitation.

The Emergency Management System is headed by the Prime Minister, who is responsible for leading disaster relief operations. Responsibilities for emergency management in Japan are shared at central, local, and city levels but are mainly based at the city level. There is close cooperation with fire stations and traffic and land authorities as the Disaster Prevention Bureau centrally coordinates emergency services. According to the government's national poll in 2013, Japanese citizens also recognise the importance of striking a balance among self-help, cooperative help, and public help for disaster resilience, rather than solely depending on public help (Cabinet Office 2016).

Following a disaster, there is an explicit protocol of disaster management to follow. Moreover, the protocol includes the active participation of local communities in assisting the local government in disaster management (Cabinet Office 2016). 
As an example, there is a network of emergency management services within Iwate prefecture that also involves community-level volunteers in rescue activities and self-evacuation protocols at the community level in Japan. Residents are encouraged by their local government to become more proactive and involved in community preparation for disasters, especially after the Awaji earthquake in 1995 (Bajek, Matsuda \& Okada 2008). Typically, residents form part of self-governed neighbourhood organisations, known as 'Bou-Komi', meaning disaster reduction and community organisation. As machizukuri organisations, these local organisations greatly facilitate the organisation of disaster response and reconstruction.

Natural disasters are part of everyday life in Japan. As discussed above, government organisations have been actively working on disaster risk reduction and mitigation activities in communities across the country for decades in preparation for the next earthquake or storm. For decades, residents have been actively participated in disaster risk reduction through volunteering activities administrated by selfgoverning bodies located around villages and towns (JICA 2017).

Japan experienced a proliferation of volunteer groups in the wake of the Hanshin-Awaji earthquake in 1995. The government enacted legislation in 1998 to help manage the growing number of civil society groups dedicated to this and related purposes - the Promotion of Specified Non-profit Activities Law (Tokutei Hieiri Katsudo Sokushin Hō) reflecting the general trend in post-disaster strategy and community development in Japan, especially in rural areas and smaller communities. The remarkable level of volunteerism and relief efforts in response to the 2011 disaster can only be understood considering the lessons learned from 1995. The growth of volunteerism and non-profit organisations after the earlier Awaji earthquake was the foundation for volunteer mobilisation after the GEJET disaster (Mullins \& Nakano 2016).

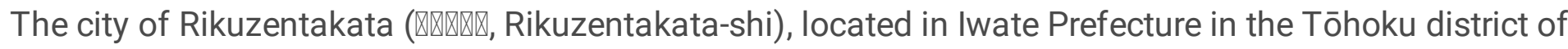
Japan, was an example of this kind of mobilisation in the wake of the GEJET disaster. Prior to the GEJET disaster, the population here was around 24,000 residents. In the 2011 disaster, nearly 1,800 died, and 213 were reported missing. As in many other rural parts of Japan, the city was also experiencing population decline more generally and an ageing population. The city comprises a small tract of lowland plains along a low shoreline encircled by highlands. The tsunami demolished the lower-lying areas of the city, and every house was destroyed. Despite the severity of the damages, the town experienced a significant revival in the years following the 2011 earthquake and life continued in the small town.

Hence, the Tōhoku region was selected for this case study due to its location as the initial centre of relief activities and ongoing work in this area. Before the disaster, the coastal area was an industrial region with primarily labour-intensive industries focused on fisheries. Following the disaster, the coastal areas of Iwate Prefecture were the target of extensive government intervention and political manoeuvring and the focus of grassroots and community action to foment recovery.

\section{Case Study: The Machizukuri Initiative And The 2011 Gejet}




\subsection{Data Collection}

The main data source for this study was face-to-face interviews with individual humanitarian stakeholders about their post-disaster experiences and perceptions of recovery in Rikuzentakata-shi. Fieldwork was carried out in Japan, Iwate Prefecture, in 2017, during which time the principal author travelled to the coastal areas in Iwate.

\subsection{Participants}

Participant selection was purposeful and we aimed to recruit humanitarian professionals who played a key role in the local context and contributed to the recovery and relief efforts in Iwate Prefecture following the GEJET.

The sample of research participants was limited to senior managers who held decision-making positions in non-government organisations (NGOs) and non-profit organisations (NPOs) that provided direct relief and recovery assistance following the GEJET. Senior management staff were targeted due to their unique positions within their organisation and their ability to provide a range of perspectives surrounding various decisions, in addition to providing their personal experiences of the disaster and recovery efforts.

Four organisations that were members of the machizukuri initiative and four non-members were chosen to provide comprehensive data regarding perceptions and experiences. Each participating organisation belongs to the network of emergency management services within Iwate Prefecture that was oriented towards disaster response relief activities and provided information for residents through local community channels.

\subsection{Ethical Approval}

Ethical approval was received from the Royal Melbourne Institute of Technology's (RMIT) Human Research Ethics Committee prior to commencement. Informed written consent (in English and Japanese) was obtained from each participant prior to conducting the interview.

The interviews focused on understanding stakeholders' post-earthquake and tsunami experiences of relief and recovery operations. A series of pre-designed semi-structured interview questions were used to guide the interviews and gain an in-depth understanding of participants' viewpoints regarding recovery efforts and their attitudes towards government policies and actions at that time. Questions were included to understand the role and contribution of the machizukuri initiative to the relief and recovery efforts including details of what worked well and what didn't work as well.

The principal author, a practitioner in humanitarian disaster relief, interviewed all eight stakeholders who reconstructed and described the disaster relief and recovery efforts and the issues involved. A qualitative approach was adopted to gain a deep understanding of their experiences and obtain rich and holistic insights into participants' views and actions at that time. Interviews took between 1 hour and 1 hour 45 minutes. 
All interviews were recorded and transcribed verbatim? Thematic analysis was undertaken to identify and analyse patterns within the data and subsequently identify major themes. Each interview was read several times by the first author following transcription. Interview results were sorted and coded according to the key questions and any

additional responses were added to the appropriate section so that all related responses were examined together.

\subsection{Participants}

Eight humanitarian professionals who held a senior position in an aid organisation that played a key role in the relief and recovery efforts following the GEJET completed an interview. The majority were male (75\%); all had a minimum of five years' work experience in that or a similar role, and each managed between 20-30 staff in 2011-2012. They had all experienced the earthquake and the effects of the tsunami themselves and were acquainted with families and survivors that had moved from disasteraffected zones. Table 4.1 provides a summary of the participant's characteristics including the role each held in their organisation. Pseudonyms have been used to protect study participant confidentiality.

Table 4.1: Participant information 


\begin{tabular}{|c|c|c|c|c|c|c|c|}
\hline $\begin{array}{l}\text { Name - } \\
\text { Pseudonyms }\end{array}$ & Gender & Org & $\begin{array}{l}\text { Experience } \\
\text { (Year) }\end{array}$ & Position & $\begin{array}{l}\text { Role and } \\
\text { Responsibility }\end{array}$ & Machizukuri & Staff \\
\hline Mr Takashi & Male & NP01 & $5-10$ & Director & $\begin{array}{l}\text { Management } \\
\text { and } \\
\text { coordination }\end{array}$ & - & 30 \\
\hline Mr Nobuo & Male & NPO2 & $5-10$ & $\begin{array}{l}\text { Supply } \\
\text { Officer }\end{array}$ & $\begin{array}{l}\text { Risk } \\
\text { mitigation } \\
\text { and response }\end{array}$ & - & 30 \\
\hline Mr Kaito & Male & NPO3 & $5-10$ & $\begin{array}{l}\text { Head of } \\
\text { Program }\end{array}$ & $\begin{array}{l}\text { Response and } \\
\text { recovery }\end{array}$ & Member & 20 \\
\hline Mr Sato & Male & NPO4 & $5-15$ & Director & $\begin{array}{l}\text { Program, aid } \\
\text { support and } \\
\text { relief }\end{array}$ & Member & 35 \\
\hline Mr Ohba & Male & NG01 & $5-15$ & Director & $\begin{array}{l}\text { Program, aid } \\
\text { support and } \\
\text { relief }\end{array}$ & Member & 30 \\
\hline Mr Michi & Male & NGO2 & $5-10$ & $\begin{array}{l}\text { Program } \\
\text { Officer }\end{array}$ & $\begin{array}{l}\mathrm{ICT}^{*} \mathrm{~S}, \\
\text { response and } \\
\text { recovery }\end{array}$ & Member & 35 \\
\hline Ms Yuki & Female & NGO3 & $5-15$ & $\begin{array}{l}\text { Head of } \\
\text { Agency }\end{array}$ & $\begin{array}{l}\text { Management } \\
\text { and } \\
\text { supervision }\end{array}$ & - & 20 \\
\hline Ms Akira & Female & NGO4 & $5-15$ & $\begin{array}{l}\text { Head of } \\
\text { Agency }\end{array}$ & $\begin{array}{l}\text { Coordination } \\
\text { and } \\
\text { leadership }\end{array}$ & - & 25 \\
\hline
\end{tabular}

*ICT - Information Communication Technology

\section{Results}

\subsection{Key Themes}

Data analysis identified seven key themes which we have labelled: The scale of GEJET overwhelmed disaster preparation efforts, Disconnection between Central Government and Local Organisations, Selfreliance - the local community rises to the challenge, Machizukuri: Addressing Different Levels of Risk and Vulnerability, Local Knowledge of Specific Needs, Mistrust and Other barriers to Resilience, and Gaps in Assistance

Theme 1: The scale of GEJET overwhelmed disaster preparation efforts: An important theme that emerged from the data was the inadequacy of previously effective preparation efforts in the face of the GEJET. While Japan has a solid disaster response system, and its communities undergo regular preparedness drills and practice disaster scenarios and awareness workshops to ensure they are able to cope when disaster strikes, they were unprepared for the GEJET. Several participants spoke about the importance of practice drills in ensuring the community is well prepared for a disaster. The drills and 
practice efforts are based on the most likely scenarios and are based on hazard maps and have been effective in preparing for previous disasters including earthquakes, floods, and tsunamis. Examples of direct quotations from participants supporting this theme are presented in Table 6.1.

However, the enormous scale of GEJET meant that they were not prepared, and without enormous effort, could not adequately prepare for such an unexpectedly destructive disaster. There was a consensus among all participants that the preparation undertaken was insufficient. For example, Ms Endo Miki, an emergency worker, had to communicate tsunami warnings to the townspeople with her shouts.

Unfortunately, she lost her life in Minami Sanriku's crisis management centre, where the powerful tsunami washed away everything (McCloskey 2011). She is credited with saving seven hundred lives. This example shows how the practices in place were inadequate for a disaster of this magnitude.

An example of how the Disaster Preparedness Program worked well at the local level is when more than 3000 school children safely evacuated to higher ground and survived despite the intensity of the tsunami and how quickly entire sections of towns were destroyed. The students had prepared in community disaster preparedness programs and received training in helping the more vulnerable and using meaningful and flexible judgement in disaster scenarios. For example, in Kamaishi-city on north-eastern Honshu (one of the worst impacted cities with about 1200 residents reported as missing or killed by the tsunami), almost all the elementary and junior high school students survived when they acted according to the concept of 'tsunami tendenko'. Tendenko is a dialectal expression that means 'go separately' and calls for a quick evacuation if a tsunami hits without attempting to help others, family, children and parents.

The concept was a product of several years of training in disaster education that was part of a school program established in 2005. The tendenko concept flourished on the eastern coast of Japan as a grassroots response to large-scale disasters. The word tsunami tendenko has been handed down and circulated in the Tohoku region as an important code of action to be observed in local communities at risk of tsunamis (Kodama 2015).

Table 6.1. Examples of quotes in relation to Theme 1 
During education and drill exercises, people learn about the importance of knowledge in emergencies. People are educated about worst-case scenarios, especially for tsunamis when there is only a very short time available to evacuate. [Mr Nobou, NPO]

I was here for the previous incidents ... in this one ... though we had drills, we were not very ready. Due to the level of waste for two days, so much debris was hard to clean, and it was difficult to reach the evacuation centres. My daughter's school disappeared, and we had no food. Whilst government officials arrived, they didn't ask us what we should do. They know we have experienced other events, but we wondered why they didn't ask us in this one? They didn't ask us what good ideas would be. [Ms Yuki, NPO]

We participated in several routine emergency drills, such as residence fires, traffic accidents and response to these emergencies. Often, we adequately participated and practised. However, we haven't participated in unusual emergencies, such as unexpected and destructive disasters or crises. [Mr Sato, NGO]

The GEJET was considered a novel emergency, and such events require and demand 'adaptive leadership' if they are to be met with effective countermeasures (Howitt \& Leonard 2009, p. 617). The disaster area, particularly the Sanriku area, is considered well prepared for disasters and tsunamis based on past experiences. However, several issues emerged after the 2011 disaster. For instance, the disaster was much more widespread than anticipated, and there was damage and injury in areas considered outside the zones of highest risk. These areas were less prepared for the effects of the tsunami.

Evacuation drills aim to improve disaster evacuation skills among the population. Government organisations such as the Japanese Red Cross Society, with cooperation from the disaster risk reduction organisations in the central and local governments, along with the resident organisations (NPOs) in the community, developed a disaster risk reduction plan that includes evacuation drills and warning systems at the village level. This plan included various initiatives such as 'self-help', which compels residents to know what to expect in the wake of a disaster and to understand the associated risks. They should be proactive and warn others instead of waiting for official orders to evacuate or seek shelter, for instance. Other initiatives include 'mutual help', where they make evacuation plans as a community. Local residents understand and use disaster risk information to forge effective and accurate plans.

Several evacuation systems are used in disaster scenarios to enable all residents, including those who require special consideration, such as women, children, and people with disabilities can protect themselves from disasters and evacuate safely. However, rural Japanese culture tends to be male dominated. Men have a high degree of contact with individuals outside of their household, but women are less connected and more centred in the home and family. Each community's norms may differ from other communities; hence, conflicts may occur regarding gender and individual roles within the community. School children and infants are also members of the population who need special support, so evacuation plans, disaster education and drills are tailored to their capabilities and safety. 
. Although the Japanese government immediately responded in the aftermath of the earthquake and tsunami under the existing emergency response systems, which were already quite robust given Japan's history with such natural disasters, they were forced to amend existing laws and enact several new laws and regulations to expand those systems due to the sheer magnitude of the GEJET disaster.

\section{Theme 2: Disconnection between Central Government and Local Organisations}

Interviewees frequently spoke about a lack of coordination and disconnection between the central Japanese government and local organisations which we have identified as Theme 2.

While the coastal areas of Iwate Prefecture were the focus of extensive government intervention and political manoeuvring, and as response efforts continued beyond the immediate aftermath period, the government of Japan shifted focus towards greater engagement with the local community in the affected areas.

There were, however, considerable difficulties as the government struggled to connect with post-disaster communities effectively and the reported lack of coordination and connection between the various groups hindered recovery efforts and created frustration for those concerned. Some examples of participants' reports of some of the difficulties are presented in Table 6.2.

Table 6.2 Examples of participants' quotes in relation to Theme 2

What a stimulating scene. That wasn't planned work because the public sector repaired some damages successfully, others not as much. In particular situations, fishermen volunteers and other agents were able to come together to achieve collective actions. [Mr Sato, NGO]

Responses were really slow and required approval for most applications we did. The relief efforts get hung up waiting on official permission, and [it] takes [more than] a day before we can access more support. [Mr Nobuo, NPO]

Waiting a lot. They would not let us move on or progress without going back to the officials despite the need to react quickly. [Mr Nobuo, NPO]

The capacity of the existing systems could not be reinforced. We were left in the middle of the devastations with no supplies. [Ms Akira, NPO]

Organisations struggled to support the survivors and perform essential relief; for example, relocating food and relief supplies or distributing necessary items because they lacked the resources and did not have the implementation capacity of the central government. This difficulty may have been due to their propensity to work independently of other organisations on specific issues. Some also reported a disconnect and a lack of coordination between different relief organisations in Iwate Prefecture, delaying much needed assistance. Participants expressed their frustrations regarding slow response times and a lack of response from the authorities. One participant expressed her surprise that little input was asked of local community residents as the scale of the disaster seemed to overwhelm authorities at all levels despite the planning and preparation. 
Slow responses or a lack of responsiveness from the government led to delays in securing needed resources. Since Japan is a disaster-prone country, most municipalities had appropriate stocks of emergency food and supplies in their storehouses before the disaster. Yet, many of the emergency supplies in the affected area were washed away or otherwise damaged or destroyed. While there was an urgent need for replenishment that was not considered in the drills and preparations, the response at the prefectural and national levels, including the supply of services for residents and the provision of housing, was extremely slow.

A lack of coordination among different scales of operation was apparent that prevented a coherent response to risk associated with damaged infrastructure, closed roads, loss of fuel, lack of health care support and paralysis of supplies. Due to communication and information sharing problems directly caused by the disaster, integrated relief activities became complex and difficult to carry out, and there was confusion about the severity of the damage in the affected areas and regions.

Moreover, the failure of communication systems and power in many areas led to difficulties in reaching survivors. Also, the failure resulted in perceptions of the dysfunctionality of local organisations in sharing precise information among their colleagues. Regular reform in disaster practices, on the other hand, will enable the government to forecast long-term risk mitigation and take proper action.

\section{Theme 3: Self-reliance - the local community rises to the challenge}

The support and effectiveness of local organisations and the community in responding to the GEJET was a frequent theme throughout the interviews, which we have labelled 'Self-reliance - the local community rises to the challenge'. Some examples of participants' quotes relating to this theme are reported in Table 6.3 .

Japan regularly experiences floods, landslides, and smaller earthquakes that typically cause only minor damage. Japan has habitually overcome the more severe disasters with the help of strong community linkages, social capital, leadership of local communities and a strong governance support system. The Kobe (Hanshin-Awaji) earthquake of 1995 was a definitive moment in the development of local relief cultures such as volunteering and civil society in contemporary Japan. Major lessons learned from the Kobe disaster became templates for various relief groups to prepare for and respond to future disasters.

However, the 2011 GEJET disaster inundated a far wider range of areas than those anticipated in the existing hazard maps and disaster planning. People who lived in areas that had not been specified as susceptible to hazards attempted to evacuate too late as it seemed unlikely the tsunami waves would affect them directly and many of the casualties were from those areas. While, the disaster created a greater sense of collective vulnerability among residents, it also forced them to become more self-reliant and ultimately more resilient.

Due to the catastrophic scale of the tsunami in coastal areas, people lacked food, supplies and basic services like medical attention because of the paralysis of logistics in the inland areas. Residents were 
left to fend for themselves in difficult situations, and the provision of essential supplies and services collapsed in the days and weeks following the tsunami most survivors lost family, friends, homes, and property. Many elderly residents were unable to obtain their daily medications.

Unprecedented levels of support were needed to help survivors meet their daily needs, clear massive debris, and re-establish destroyed areas. Judging by the residents' accounts of the lack of coordination and scarcity in some relief supplies like food and clean water, municipal governments could not address the scale of the disaster in all its dimensions and it seems the government was deficient in mobilising existing networks. It, Due to limited public help and support from the government, neighbours, residents, and their communities were the first responders, and community residents supported the tsunami survivors by evacuating them to safety and providing food, water and shelter. This highlights the importance of self-help and cooperative help in each community (Sakurai \& Sato 2018), in which people showed solidarity and worked together, reflecting the notion of Kizuna (having a social bond or connection).

The government's recovery efforts included several slogans or sayings meant to help motivate the local population. For instance, the term 'Kizuna,' meaning social bond or connection, was central to the local campaign slogan 'Ganbarō Nippon!' (Let's do our best, Japan!) and reflected norms around collectivereinforcing imagery. Similarly, the Tōhoku phrase 'Ganbapesshi', translated as 'try hard' or 'keep going', was used. Other terms, including 'Moyai' (coming together) and the concept of 'Kizuna- $\bigotimes^{\prime}$ (enduring bonds, close relationships), became central to conveying the spirit of a community joining together. 'Kizuna' was chosen as Japan's kanji (ideogram or script) of 2011 because it best symbolised the resilience of the communities in disasters (Tokita 2015). It was also used as the title to a symposium held at the University of Tokyo in 2015 as it embodied the idea of community recovery. The notion of kizuna was ubiquitous in Japanese popular culture even before the 2011 GEJET disaster and, therefore, a readily incorporated social referent. It also was prominent in the broader sense after the 2011 GEJET disaster discourse. These initiatives motivated people living outside the affected regions to support the victims through financial donations and volunteering efforts.

Another factor was the cultural dimension and the use of notions like 'Kizuna - the bonds of friendship' to build resilience. The term evoked a sense of national and international solidarity in the face of hardship and was combined with the expressions Gaman (endurance) and Gaman-Zuyoi (resilience). The concept of Kizuna was also considered coterminous with stereotypes about the Japanese national character, which is perceived to be group-oriented with a unique ability to withstand adversity and a strong sense of community (Suter 2016, p. 305). A clear disconnection appeared in the government response to the disaster, which increased the vulnerability of residents.

Table 6.3 Examples of participant quotes in relation to Theme 3 
We don't think we've ever seen this situation of how vulnerability can be mitigated by our culture before. Our inherited behaviour starts appearing. [Ms Akira, NGO]

I just hated to knock on the doors and ask: "Are you okay? Are you safe?" I think they are just inappropriate questions to ask. Instead, I asked the survivor: "Is there anything we can help you with?" Even if they don't feel good, they may feel more comfortable. [Ms Akira, NPO]

Community organisations started to accept donations of supplies regardless of the source [so when] we realised trucks were coming, [we] unload[ed] supplies in our warehouse. We sorted those supplies and stored them. We prepared the supplies according to the needs of every team to avoid disruptions and bottlenecks of relief priorities. [Ms Akira, NGO]

There were ten fishing ports around Kamaishi city and surrounding villages. First of all, I went to each village and asked them to make a list of items they need[ed]. Then, the next day I collected the list, and according to the list, we sorted and classified the supplies for each village. This is how we supported each other. [Mr Takashi, NPO]

The responses and actions of local community members following the GEJET were critically important to the recovery effort and was referred to by several participants. Local organisations were able to help others and used community solidarity as a tool to help mitigate and provide assistance to residents in trouble. Participants observed that the self-help and community-driven practices embodied in the machizukuri resulted in various projects and efforts, including planning initiatives, neighbourhood-level actions, and urban development, that integrated local culture. These efforts helped to focus on the particularities of Japanese cities and emphasised the resilience of the communities.

Over the years prior to 2011, a collaborative, integrated community participatory approach was developed in the machizukuri as local community groups with wide-ranging expertise assisted in cities, towns, and villages in the Tōhoku region. The machizukuri also represents a long-term commitment to the community and the responsibility and involvement of all stakeholders in community development and reconstruction of the affected area. In the GEJET disaster, machizukuri organisations were important because they fostered community care and citizen participation. Community organisations were set up in situ and facilitated community care by emphasising the tangible and intangible aspects of community recovery post disasters. Members were empowered to help other members.

The people of Tōhoku were commended for their strength and resolve in the recovery. They were admired for their perseverance (known as gamanzuyoi) and the resilience they displayed following the disaster. There was a focus on community, and crimes like looting were low to absent in the recovery. Neighbours helped their fellow community members instead of taking advantage of the chaotic circumstances for personal gain.

People gained power through strengthening resilience among those affected. A total recovery would require time and strength from the area's residents. In addition, Buddhist groups and worship centres provided community support and spiritual care after the 2011 GEJET crisis, fuelled in part by research into the role of religion in health care and care for the dying. These spiritual care approaches contributed to addressing the needs of disaster victims initially and embraced the caring nature of the Japanese culture which helped people cope with the situation and adapt, despite feeling vulnerable. 
Further evidence showed a definite focus by relief organisations on meeting the needs of each survivor. There was a strong emphasis on conducting a needs assessment to assess what relief items residents needed. However, relief workers were aware of the need for sensitivity when asking people about their needs - see the example provided by Ms Akira in Table 6.3.

She reported trying to empathise with the residents she contacted and acknowledged that many residents were able to find safety. However, they still needed assistance with other dimensions of their lives due to the multidimensionality of the disaster and the extent of the devastation. One participant explained, while the earthquake struck and caused damages, a sense of solidarity was created in the aftermath, and people started donating supplies.

Her local organisation made an effort to know the needs at the community level and fomented solidarity among the disaster-affected population. When community and individual behaviours change due to the circumstances of a crisis, they seek collaboration across individual and professional groups to rebuild from their culture and cope with or adapt to shocks or crises to foster a more sustainable response.

Here, part of being resilient in the wake of such disasters is to appeal to humanitarian work in supporting the local communities and response efforts (Robertson et al. 2021). The local community organisations were trusted by residents and responded collectively to the disaster through local donations to secure what was most needed and meet the different needs of survivors, such as food, water, and healthcare support.

Moreover, participants explained it as a way of perceiving things positively in such a situation. The themes that link these examples are solidarity and helping to distribute resources in the ensuing days and weeks after the disaster, but it is not only a matter of solidarity per se. Perhaps this is important in terms of explaining resilience because it provides a concrete example of how a community can build resilience through community linkages. Aldrich (2012) showed how community ties and local civil society are decisive factors in determining a community's resilience to disaster and coordinating recovery and rebuilding. A properly coordinated, planned, and decisive recovery policy with well-thought-out participation of different stakeholders would have been useful and efficient. This feedback regarding local responses to the disaster in Japan shows there was resilience at the local level, and communitybased organisations helped to support that. Still, the scale of the loss and the scope of recovery was significantly greater than planned for.

\section{Theme 4: Machizukuri: Addressing Different Levels of Risk and Vulnerability ('unimaginable' (soteigai))}

The issue of vulnerability and different degrees of risk faced by various members of the community was another important theme identified through the data.

Disaster relief operates in the context of communities that have different levels of vulnerability and with populations and individuals within populations that experience different levels of risk. The general understanding was that local communities were prepared to cope with disasters like tsunamis because of 
machizukuri practices that exist in most Japanese cities. However, disaster relief is inherently linked to the vulnerability levels of local communities (komyunitei). As people faced the local circumstances of the earthquake, they were exposed to different degrees of risk, and they faced different challenges.

In this context, vulnerability to risk is viewed at the individual level. People were exposed to numerous risks in their localities and confronted with different challenges. There was a lack of employment opportunities in the aftermath of the disaster, for example, and core industries such as aquaculture and the processing industry in Rikuzentakata faced recruitment challenges and other problems. A great deal of land in the region became overgrown with weeds. Most importantly, the downtown area of the city was lower than other areas, which exacerbated human suffering during the evacuation. However, residents who lived near higher ground survived because they could evacuate successfully, even as they saw the tsunami unfolding.

The evacuation and rescue methodologies for disasters include special consideration of some groups including the elderly and people with disabilities (both physical \& mental disability, for example, dementia, can place people at a greater risk of injury) or medical conditions who are more vulnerable and prone to injuries and are more likely to suffer harm and need more attention due to the harsher living conditions in evacuation centres, especially in unusually cold weather.

Evacuation teams, for example, from Otsuchi city and several other cities and towns, were reported missing or killed. The tsunami struck them after they evacuated from the earthquake. They felt responsible for leading survivors to higher ground rather than evacuating themselves.

Moreover, high death rates among aged people in Iwate Prefecture were flagged as a significant issue, as the elderly and people who need health care are less able to evacuate quickly. Evacuation centres were overcrowded due to the huge number of evacuees.

Table 6.4 Examples of participant quotes in relation to Theme 4

Unequal distribution of risk and unequal distribution of reconstruction efforts made residents more vulnerable. [Ms Yuki, NPO]

Due to specific particularities of Japanese cities, machizukuri [community building] community practices played a vital role in promoting community activities, including a strong emphasis on the neighbourhood in attempts at making a community space. [Ms Akira, NPO]

Cultural dependency such as the term machi as a place of a social community is deeply rooted, which relates to how people perceive their place in communities. [Mr Obha, NGO]

Expected improvements include further community-driven initiatives, further decentralised actions in the cities and more effective use of machizukuri attempts. [Mr Sato, NGO]

The elderly and sick people were susceptible as many had to suffer overcrowded temporary shelter settings and several transferred to hospitals during evacuation. [Mr Sato, NGO]

\section{Theme 5: Local Knowledge of Specific Needs}


Understanding vulnerability played a major role in both the initial response and ongoing relief efforts, particularly through the collaborative efforts of non-profit organisations in the region. Machizukuri was viewed through a cultural lens and provided a way to understand how culture shaped vulnerabilities.

As the communities coped with the disaster, the main concern initially was assuring the safety of the survivors. Several organisations had shifted their focus and started to prioritise assistance for women and the elderly. For example, some organisations provided household items that were damaged or lost, and some focused on re-establishing healthy routines for children and helping their families.

An eclectic number of strategies were employed to help meet the different needs of residents and to address the multi-faceted problems that the community faced in the period following the disaster. Local participating organisations understood what different segments of the population needed and how local organisations could help. For example, local knowledge and awareness of the difficulties people faced allowed aid organisations to understand the specific need for bicycles to allow people to move around (see Table 6.5). They also knew how resources could be distributed and allocated to people whose own capacity to cope was strained.

Part of the process of understanding the demands was determining what types of supplies were needed and if the support was suited to the specific culture of Japan. This approach is consistent with the Japanese culture, understanding the trauma of a disaster situation and showing compassion, generosity, and effectively governing the relief operations.

Table 6.5. Examples of participant quotes in relation to Theme 5

The stories of various reporters, when viewed within the context of Japan's collective culture, the many leaders, volunteers, and community members that contributed to the relief production, all represented opportunities for social engagement as machizukuri objectives. [Mr Ohba, NGO]

Our project aimed to provide particular materials such as bicycles so that survivors could move around. [Ms Akira, NPO]

Some Japanese aid organisations helped in providing household equipment such as fridges and washing machines and those kinds of things, and other NGOs just focused on children. They made temporary playgrounds and that way they supported the families. [Mr Ohba, NGO]

We had neighbourhood associations (known as Chonaikai), volunteers and local participants coming from everywhere to provide help. No matter what they did, they lent their knowledge and efforts to show solidarity. Kizuna. [Ms Yuki, NPO]

I believe that Japanese neighbourhood associations showed a strong emphasis on the elderly and disabled population as they could not evacuate themselves. [Mr Oba, NGO]

\section{Theme 6: Mistrust and Other barriers to Resilience}

The issue of mistrust creating a barrier to resilience emerged as an important theme from the interviews. Despite the existence of long-standing community-level organisation and mobilisation for improvement in local infrastructure and community resources such as the machizukuri initiative [वसाप] (Menoni et al. 
2012), many of the local actors were not recognised as community leaders because their social engagement fell outside of the existing framework of community disaster response. This lack of recognition left them vulnerable in the wake of the crisis, and it made them less resilient as a community as the effects of the disaster wore on.

While the government played a vital role in the evacuation and response efforts and apologised to the victims for its slow response, survivors developed a sense of mistrust due to the lack of information regarding the damage the tsunami caused and the explosion of the nuclear reactors. They often received confusing explanations from authorities and

felt ignored and confused, completely disconnected from family and community as limited information on the scale of the damage was provided to them by the officials. Survivors wanted to perceive a sense of normality.

Moreover, participants referred to a lack of national government preparedness, a lack of organisation at prefectural levels, and an overall lack of effective decision-making. Interviewees also referred to a lack of consultation with local communities regarding restructuring and relief efforts that further contributed to a lack of trust. Several examples of participant's quotes supporting the theme of mistrust are displayed in Table 6.6.

The structure of the community relating to norms and practices may partly explain the lack of consultation as the relief and response were not localised, and researchers have emphasised the grave impact this had on the social bonds between community members in the GEJET affected areas (Kaneko 2013). The region suffered an exodus of the population beginning in early 2013.

Participants described many inconsistencies in operations, realising the difference between government rhetoric and actual action, while it was also acknowledged that the government had many competing interests to attend to as the disaster unfolded and relief was underway. Still, they felt the government ignored their participation as a source of support.

Therefore, using a centralised approach alongside priorities in relief engagement demonstrated the politicised nature of disaster relief that has left several communities and organisations feeling excluded from participation in the relief operations.

The key factor for most people is that up until the end of 2015, much of the recovery was focused on infrastructure projects for the benefit of the community and its development. For example, temporary housing, public housing, rebuilding schools, and the hospital were larger projects that did not necessarily facilitate participation because the central government did not formulate appropriate guidelines on priorities. Despite extraordinary reconstruction efforts, people's recovery has stagnated and

survivor's other needs, including health issues, both physical and mental, job losses and other were neglected. While reconstruction was important, other significant disaster-related issues were not prioritised. The centralised approach to the disaster left the major budget in the central government's 
hands. Localities and communities used their own budgets to plan their own priorities, but those resources were inadequate given the scale of the disaster.

Table 6.6 Examples of participants quotes in relation to Theme 6

Iwate Prefecture is so big. The affected area is quite long, from Iwate Prefecture down to Miyagi, Fukushima, Ibaraki, those prefectures. The first job they had to do was to collect all the materials and supplies they needed, which was the first thing they did. Early-stage, that's March 15th, so four days later. This was the early stage of the activity. Only a small volume of the materials came. Supplies came to the office, including medical supplies. [Mr Sato, NGO]

Everyday life becomes extraordinarily different. This needs more support. [Mr Nobou, NPO]

The disaster forced people to change their lives. Daily disparities were greatly affected by the earthquake. Disaster, evacuation, reconstruction, living, and economic disparity. What remained until the end was a reconstruction of the mind. Mental health. [Ms Kako, NGO]

I think the attention devoted to the economic element of this disaster is not an issue. The impact of this disaster is huge on everyone in this country. However, we believe we were ignored, even deliberately left out of consultation and support. [Mr Kaito, NPO]

Perhaps, we were misled by viewing ourselves as superior. Our country's political position in terms of strength and weakness were clearly exposed after the disaster. [Mr Sato, NGO]

Remarkably after the disaster, our country requires decentralisation of both political and economic structures. In particular, the Fukushima Daiichi nuclear power plant crisis drew significant criticism to the nuclear-power production in Japan. [Ms Yuki, NPO]

The central government did not show adequate knowledge of specific regional needs, as communities and local leaders used their own resources to finance reconstruction efforts. [Mr Nobou, NPO]

\section{Theme 7: Gaps in Assistance}

We have labelled the seventh and final theme from the interviews as 'Gaps in Assistance' and some examples of participants' comments can be seen in Table 6.7.

One of the roles of the government in disasters is to facilitate the delivery of food, which was very scarce in the immediate aftermath of the GEJET, and relief items to evacuation centres in the affected areas. Supplies like this were consolidated at Japan Self-Defence Forces JSDF sites (50 sites nationwide), and JSDF ultimately delivered these supplies to the affected areas. However, in practice, the delivery of aid was more complex, and while the government focused on providing evacuation centres and temporary housing, this was not a priority among the residents at the time. Resources were not mobilised in ways that considered the local community. Yet, the response guidelines gave the highest priority to saving human lives. With the loss of community connections (tsunagu) and close neighbourhoods, people emphasised the social linkages despite having busy lives and jobs. Survivors and their families were separated in the evacuation process, and the lack of information resources put them under stress.

Although mechanisms were in place in Japanese rural society that were intended to respond to disaster situations (such as Japan's Emergency Management System and Risk Reduction - The Disaster 
Countermeasures Basic Act), the government desired to take control of the relief rather than leave it in the hands of the local community (Cabinet Office 2016). Many called upon the government to pay closer attention to the needs of local residents.

The government did not amend their approach to the disaster in general nor to the specific issue of the nuclear crisis that arose. They did not allow prefectures and cities to use their own recovery and reconstruction plans.

The Japanese-planned pre- and post-disaster intervention mechanisms sought to address a variety of common problems that communities faced in an effort to learn from the current crisis and apply that knowledge in the event of disasters in the future. The emergency stakeholders worked jointly across structured approaches in the emergency response hierarchies to assess, detect and respond to the crises. This silo system emphasises the authority of leaders regardless of their education or background.

The government response across essential functions, resource allocation, communication and coordination left people under stress. Flaws were observed in the Japanese Government's communication during the earthquake and the Fukushima Daiichi nuclear disaster. The lack of clarity regarding the information released led to significant confusion at national and international levels alike, which led many to question the transparency of the government (OECD 2015)

Overall, the findings show that the humanitarian relief workers felt a deep sense of discomfort because of the centralisation of and leadership style employed during disaster relief. It prevented them from dealing with local authorities who fully understood the local governance systems and the impact of the disaster on both people and infrastructure. Although the centralised disaster response system was intended to provide a resilient model for disaster management, since communities, individuals, groups, and organisations were given guidelines to follow, there were difficulties in implementation given the scale of the triple disaster across such a wide region of Japan.

Table 6.7 Examples of participant quotes in relation to Theme 7

We did not need new evacuation centres or new temporary housing. We were facing a new crisis, and our needs were more important. Neither response nor quick decisions were effective at a time when our people were at great risk. [Mr Obha, NGO]

Governments and institutions have a responsibility to listen to and engage with local communities and include local leaders and management knowledge and practices in their approach to disaster prevention and preparedness going forward. [Mr Ohba, NPO]

We noticed the central government did not appear to be flexible in terms of our recovery and reconstruction plans. [Mr Obha, NGO]

\section{Discussion}

This qualitative research study identified seven key themes relating to the role of local communities and the machizukuri in relief and recovery efforts following the GEJET in 2011. They resulted from in-depth 
interviews with humanitarian workers who experienced the GEJET first-hand and who were involved in the relief and recovery efforts through their senior positions within aid organisations.

Themes included the ineffectiveness of previously effective disaster management plans in the face of the GEJET that devastated large parts of northern Japan. While the central government enacted their disaster response plans, responses were viewed as slow and inadequate, perhaps partly due to the loss of essential resources (i.e. stockpiles of food and other items) and disruptions in communication and transport that occurred as a result of the disaster. To compensate, local communities and organisations took action and responded to assist with relief and recovery efforts. Their local knowledge meant they were aware of the needs and priorities of local communities and respond appropriately. The machizukuri were also able to restructure themselves quickly to adapt to the new situation of a massive disaster and provide a timely response. In doing so, they successfully united local community initiatives and volunteer activities to fill a gap left by the centralized governments' approach to disaster response and relief efforts. It is an example of an effective bottom-up approach to address a critical issue. However, their efforts were hindered by a lack of coordination between the various government bodies and aid organisations as well as failures in communication that prevented a more coherent response.

\subsection{The Nature of Governance in Natural Disasters - The GEJET Context}

Many scholars who have studied earthquake scenarios in Japan have referred to the strong voluntary actions of ordinary citizens in the wake of such disasters (Fisker-Nielsen 2012; Mavrodieva et al. 2019; Payne et al. 2020). They attribute this to the strength of pre-existing organisations in the community like the machizukuri groups that typically take action to coordinate assistance and allocate resources in the wake of local disasters. The machizukuri are considered a community model for disaster relief (Mavrodieva et al. 2019) and were engaged in disaster relief efforts for both the 1995 Great HanshinAwaji Earthquake and the 2011 Great East Japan Earthquake.

However, the present article has shown that in the case of the Tōhoku region after the 2011 GEJET, there were asymmetric processes of information sharing and the scale of the disaster far outweighed the physical and monetary resources available to local organisations and local governments. The central government seemed to prioritise other aspects of recovery and failed to act on pressingly important local concerns. Similar tensions have been found in recovery efforts in other disasters worldwide, such as the devastating earthquake that struck Haiti in 2010 (Comfort, Siciliano \& Okada 2010). Nevertheless, the scale of the disaster in Japan was greater in terms of economic damage and the sheer number of fatalities.

The Fukushima nuclear power plant (cited as NPS) accident is generally acknowledged in Japan as a human-made disaster because it could have been prevented. Staff at the NPS were inadequately prepared for the likelihood of a large-scale or catastrophic earthquake and tsunami and the Fukushima NPS disaster is considered the largest nuclear disaster since Chernobyl and has influenced Japan's preferred energy resource. Moreover, the Fukushima NPS disaster emerged as "the gravest one among the three GEJET disasters. Not only Japanese citizens but also the world was amazed to see how such 
unpreparedness was allowed in a country of a global reputation for excellence in engineering and technology" (Suzuki \& Kaneko 2013, p. 2) because many of the consequences were avoidable with better planning and preparation.

The governance dimension of aid and recovery efforts is often referred to as the political dimension. Nakano (2016), for example, explains that economic liberalism policies first adopted by the Japanese government in the 1980s and the ensuing decades shaped the nature of government response to the 2011 GEJET disaster. The government was illiberal in their approach to social programs and public assistance measures, having a conservative and right-leaning posture with the public (Nakano 2016). There was a lack of prompt, transparent, and useful crisis and risk information disclosure to the public, coupled with the lack of crisis information-sharing concerning the leak of nuclear facilities. This made rescue and relief operations difficult for local populations.

Disaster responses can provide insight into the broader nature of democratic governance (Oliver \& Reeves 2015), such as when voters reward leaders with their continuing support after effectively managing a disaster. However, it would be beneficial for governments to be more proactive than reactive and make infrastructural changes to reduce risks and prioritise citizen preparedness through education (Healy \& Malhotra 2009). In Japan, many voices claimed they felt abandoned by the national government. As Mullins and Nakano (2016, p. 15) explained:

Lack of timely and accurate information from TEPCO (Tokyo Electric Power Company) has meant that many residents in the Tōhoku region and beyond are anxious about the future due to worries about health risks and food safety. Given these realities on the ground, it is understandable why many in the Tōhoku area feel abandoned by the national government, especially when it has shifted attention and resources to Tokyo and preparations for the 2020 Olympics.

Although there were extensive efforts among leaders and experts to model disaster relief and recovery efforts to this disaster, leaders with positions in Japanese society significantly underestimated the potential damage that could result from such a disaster and failed to adopt appropriate prevention and mitigation strategies. The experts and leaders had great confidence in their technologies, early warning systems and preparedness efforts. Although communications were restored within hours in some areas, most of the affected areas were unaware of the exact size and scale of the damage and destruction. Neither the experts nor the leaders had access to the real-time information, as the government did not reveal all details on the destruction, nuclear emission, and death tolls. The public in Japan came to learn of the radiation risks from the Fukushima accident several weeks later, while the overseas media disclosed probable risks or worst-case scenarios in the initial days following the earthquake and tsunami (Suzuki \& Kaneko 2013). It turned out the international media reports were closer to the truth.

The relief and recovery processes were shaped by the broader engagement of government in a political strategy - a strategy that was broader than the relief and recovery efforts themselves. This was evidenced by the decline of confidence peopled showed in government actions versus increased trust in their local government. As many scholars and practitioners assert, post facto GEJET management is part 
of government administrative reform, as finding the causes and learning the lessons will become a part of how disasters are dealt with in the future (Deverell \& Hansén 2009; Furukawa 2002). Understanding deficiencies in the existing system and sharing this analysis with stakeholders is challenging but useful in preventing losses from this kind of disaster in the future (Suzuki \& Kaneko 2016).

\subsection{Dynamic interplay: Response as a society}

Official discourse on the disaster, both in and outside Japan, praised the exceptional cohesion of the Japanese people in the face of the disaster. The media was filled with heart-warming stories of "uniquely Japanese" self-sacrifice and solidarity, such as the case of pensioners travelling to the Fukushima region to help clear radioactive waste, individuals doing rounds with donations of food and supplies, and a wide range of selfless volunteering efforts. Without in any way denying the extraordinary generosity and solidarity that Japanese citizens displayed in the aftermath of GEJET, it is important to note that what was omitted from these stories was the sense of isolation and loss that individuals experienced in the face of the sudden and inexplicable loss of their homes, their loved ones, and their livelihoods. In the effort toward national recovery, there seemed to be no room for feelings of dejection and separation (Suter 2016, p. 305)

The case of the GEJET disaster is significant from a research standpoint because the scale of the disaster was unprecedented, the levels of damage were acute, and there was massive disruption as a result. While the disaster struck in an earthquake-prone area with a mostly aging population, one distinctly Japanese characteristic surfaced. In Japan, the wisdom of elders is valued, and the elderly are seen to have life experience that gives them the resilience to survive and cope with difficult situations. Yet, Japan faces a dilemma with the ageing population with disabilities or mobility impairments that make them more physically vulnerable to disasters (Muramatsu \& Akiyama 2011).

An example can be cited from remarks contained in the government report to the International Atomic Energy Agency (IAEA) showing that information was withheld and the worst-case scenario was not disclosed to the public in order to "avoid the fear of the people or people to get panicked." The NAIIC report criticised this approach to information disclosure as "sheer arrogance" of the bureaucrats and their colluded parties (NAIIC, executive summary report, Caption p. 21). The NAIIC report criticised the "lack of people's safety first" approach and paternalism or putting "organisational convenience first" at the time of the GEJET.

By drawing on insights from Oliver-Smith (2011, p. 26) framing a disaster as a dynamic interplay of "events/processes" that involve how human societies respond to the threat of natural hazards and disasters, it is possible to see how disaster relief can open avenues of political dynamics in specific forms that benefit certain groups in society. In particular, disasters can be framed as both a threat to consolidated forms of power and a form of legitimating the claims made by human actors. Disasters can be a mechanism for developing new grounds for economic and more equitable growth within a society (Jones \& Ward 2007; Pelling \& Dill 2010). 


\subsection{Community Organisation}

Communities should have access to resources and operate autonomously in order to cope with a massive disaster like the GEJET disaster. Despite extensive planning and being highly prepared, the scale of the disaster tested the capabilities of the central government to cope with such widespread damage and loss of life. The Disaster Emergencies Committee (DEC 2011) reported the Japanese government asked international humanitarian aid organisations to forego direct assistance and extensive involvement with communities during the response and reconstruction phases; however, the Japanese government did accept initial offers to facilitate evacuation. The reality is that recovery dragged on and disrupted the fabric of many communities as they lost social bonds throughout the GEJET affected areas in Eastern Japan, as revealed in the drastic population drain occurring in early 2013 (Kaneko 2013). Less attention was given to the final stage of recovery (Galindo \& Batta 2013).

The politics are more complicated still because the national government has close ties with the Tokyo Electrical Power Company (TEPCO) that constructed and operated nuclear reactors around the country. TEPCO falsified key safety test reports and ignored early warnings regarding the earthquake-readiness of the nuclear plants in Japan. The Prime Minister was also accused of hiding a report about the possible evacuation of Tokyo, another controversy that seemed to implicate TEPCO and the national government. The decisions and choices of the national government were considered short-sighted by many of those involved in more local grassroots efforts because they left crucial decisions up to the technical leaders. The technocrats prioritised nuclear safety after the GEJET disaster and subsequently mismanaged the nuclear crisis.

While Japan is relatively resilient to disasters given its developed country status, its post-disaster relief and recovery management after the GEJET underlined social, cultural, and political problems with delineating state and capital power. The upsurge of donations made more directly and locally, and the active participation of citizens in recovery tasks led to increasing solidarity among survivors but further widened the lack of trust between people and the government. Trust is a key component of good governance, and choices and decisions made by the government may have undermined trust in them (Aldrich 2017).

The Great East Japan earthquake rekindled the debate over local government reform such as decentralisation, local autonomy, and regionalisation (Samuels 2013). The local community felt the government did not engage them in the decision-making process. In some cases, they felt excluded despite people's calls to establish bridges with the government. The participants called this bridge with the government. The government centralised their approach to better control the flow of disaster response and allocation of resources, but this left people feeling ignored as they had to work autonomously and improvise without government assistance; hence there was a loss of faith in the government.

\subsection{Vulnerability}


Vulnerability is an important concept in disaster studies as it speaks to the various dimensions of natural disasters people face, such as earthquakes or violent weather events. It is a concept used to discuss physical exposure to hazards, but there is also the notion of social vulnerability (Cutter, Boruff \& Shirly 2003; Flanagan et al. 2011). Social vulnerability draws attention to the conditions in which people live and how precarious their day-to-day existence might have been prior to a disaster, which helps to explain why they lack resources post-disaster (Thiri 2017). Wisner et al. (2004) defined vulnerability as "the characteristics of a person or group and their situation that influence their capacity to anticipate, cope with, resist and recover from the impact of a natural hazard" (Wisner et al. 2004, p. 11). Vulnerability refers to both the unsafe conditions created by the disaster event and location, but also "access" and "livelihood" to understand why some residents are more vulnerable than others (Blaikie et al. 1994).

Vulnerability is also a pervasive trope in Japanese culture. It is captured in the idea that Japan is a "small island nation" (Shimaguniron), and even in contemporary times, the Japanese people see themselves as at-risk and vulnerable in a fragile land. So, it is no surprise that this fragility became a leading element of national discourse after the GEJET. As one senior defence ministry official explained: "The quake highlighted the country risk of Japan. Without leadership and a better political system, Japan will not be good at managing crises - and there is more danger ahead." (Nobushige 2011). The expectation of future risk was ubiquitous after the 2011 GEJET.

Our findings demonstrate insufficient effort and attention was made by central authorities in coping with social vulnerabilities following the GEJET. Consequently, local organisations shifted their priorities to help vulnerable members of the community; for example, one organisation prioritised bicycles to provide survivors with the means for transport while others helped to provide temporary playgrounds for children. These examples demonstrate an effort to address different social vulnerabilities in the communities.

The machizukuri concept of community development has been successful in many dimensions of community development in Japan, but it may not be transferable to areas outside Japan. Scholars will have to adjust to this notion of participation in local development, where the needs of local communities are put first (Mavrodieva et al. 2019). Cases like the machizukuri illustrate that catastrophes are best handled when community residents are actively engaged in making decisions. Community links are important in saving lives during disasters and in post-disaster recovery.

This position is also promoted by organisations like the Organization for Economic Co-operation and Development (OECD) that encourages governments to work across sectors using a whole-of-government strategic approach to manage critical risks. Engaging society in developing resilience is also a critical aspect of modern risk management policies, from local governments to civil society and the private sector (OECD 2015). This approach is consistent with the International Health Regulations of the World Health Organization regarding preparedness for public health emergencies and their three-pronged approach: prevent-detect-respond (OECD 2015). Similar principles were adopted in 2015 by the United Nations in the Sendai Framework for Disaster Risk Reduction. It includes preparedness for public health emergencies and health systems resilience amongst its priorities. 


\section{Conclusion}

In conclusion, the involvement of local communities and organisations is critically important in the event of a disaster. Following the GEJET, the machizukuri and other community groups were able to mobilise quickly and respond in a timely manner. Local knowledge meant they also had a clear understanding of local needs and priorities. However, the actions of the Japanese government masked local efforts in the relief processes. They lost the opportunity to mobilise more local resources through organisations that fell beyond the purview of the government. There was heavy centralisation of procedures and a focus on privileged forms of power instead of coordination in disaster relief. In the wake of the disaster, local government leaders who ran relief and recovery operations issued guidelines and orders to those under their official command. This impacted other non-government organisations involved in response and relief efforts over whom the leaders exercised no official authority. The development of a contemporary and rich understanding of power relations and politics in humanitarian relief will provide insight into the methods through which the authority of decision making is legitimised and practised in the context of humanitarian relief processes.

One suggestion is to focus on resilience to natural disasters to create stronger societies in times of crisis through education and capacity building (Shah, Paulson \& Couch 2020). Disasters or crises can play an important role in resource management insofar as they make us consider other aspects of disaster response such as learning, adapting, and renewal (Berkes, Colding \& Folke 2003). This approach is more amenable to transformative views of resilience (Juncos \& Joseph 2020).

\section{Recommendations}

Disaster relief efforts should encompass all stages of the risk management cycle, from risk assessment to risk prevention, emergency preparedness and response, and recovery and reconstruction.

It is recommended that responding to a disaster be decentralised to enable a more timely response and that a truly collaborative partnership between government and local organisations be established to prepare for, and respond to disasters when they occur. The roles of all organisations involved should be clearly articulated to promote timely and coordinated action when necessary.

It is recommended that local humanitarian organisations establish local policies that do not violate established policies and laws, strive to make additional adjustments in processing, and deliver relief through adopting emergency preparedness practices. The actions to be undertaken in emergencies and crises should also be defined.

It is recommended that governments and societies focus on developing resilience in their populations through education about disasters and adequate preparation, and fostering capacity building activities at the local level. For example, urban renewal project or activities to foster a greater sense of community cohesion and belonging. 


\section{Declarations}

\section{Acknowledgments}

The author would like to thank all the participants of the research and the community organisations in Japan for their support and participation. The author would like to thank his supervisors for their insight, guidance and helpful comments and feedback on earlier drafts of this paper. The author would also like to thank the editor and proof-reader for their efforts.

\section{Disclosure statement}

The authors have no relevant financial or non-financial interests to disclose

\section{Funding}

The authors declare that no funds, grants, or other support were received during the preparation of this manuscript.

\section{Note:}

The scope of this research arose out of the primary researcher's experience in humanitarian aid and disaster relief. The researcher's experiences within the humanitarian aid field have played a large role in shaping the direction and focus of this research, also enabled the researcher to angle this research towards multidisciplinary perspectives on disaster relief. As a humanitarian aid professional with the Nation Nations, the researcher has been involved in various large-scale disaster and crisis events for more than a decade, including the Middle East, Asia and Africa, led to the start of this research and take the direction on the social constructions of disaster relief.

\section{References}

Akhtar, P, Marr, N \& Garnevska, E 2012, 'Coordination in Humanitarian Relief Chains: Chain Coordinators', Journal of Humanitarian Logistics and Supply Chain Management, vol. 2, no. 1, pp. 85-103.

Aldrich, DP 2012, Building Resilience: Social Capital in Post-Disaster Recovery, The University of Chicago Press, Chicago, IL, USA.

Aldrich, DP 2017, 'Trust Deficit: Japanese Communities and the Challenge of Rebuilding Tohoku', Japan Forum, vol. 29, no. 1, pp. 39-52.

Aldrich, DP \& Meyer, MA 2015, 'Social Capital and Community Resilience', American Behavioral Scientist, vol. 59, no. 1, pp. 254-269.

Berkes, F, Colding, J \& Folke, C 2003, 'Introduction', in Navigating Social-Ecological Systems: Building Resilience for Complexity and Change, Cambridge University Press, Cambridge, pp. 1-32. 
Blaikie, P, Cannon, T, Davis, I \& Wisner, B 1994, At Risk: Natural Hazards, People's Vulnerability, and Disasters, Rutledge, New York.

Blaikie, P, Cannon, T, Davis, I \& Wisner, B 2004, At Risk: Natural Hazards, People's Vulnerability, and Disasters, Routledge, London.

Button, G 2010, Disaster Culture: Knowledge and Uncertainty in the Wake of Human and Environmental Catastrophe, Left Coast Press, Walnut Creek.

Cabinet Office, C 2016, Disaster Management in Japan 2016, <http://www.bousai.go.jp/kyoiku/panf/pdf/WP2016_DM_Full_Version.pdf>.

Comfort, LK, Siciliano, MD \& Okada, A 2010, 'Resilience, entropy, and efficiency in crisis management: the January 12, 2010, Haiti earthquake', Risk, Hazards \& Crisis in Public Policy, vol. 2, no. 3, pp. 1-25.

Cosson, C 2020, 'From a Tsunami-Devastated Zone to an Attractive Fishing Town: A Study on Onagawa's Strategy for a Prompt Recovery', Urban Geography, vol. 41, no. 5, pp. 777-790.

Cutter, SL, Boruff, J \& Shirly, L 2003, 'Social Vulnerability to Environmental Hazards', Social Science Quarterly, vol. 84, no. 2, pp. 242-261.

DEC, DEC 2011, 'Japan earthquake and tsunami update', vol.

Deverell, E \& Hansén, D 2009, 'Learning from Crises and Major Accidents: From Post-Crisis Fantasy Documents to Actual Learning in the Heat of Crisis', Journal of Contingencies and Crisis Management, vol. 17 , no. 3, pp. 143-145.

FDMA, FaDMA 2019, Summary Report of 2011 Tōhoku Region Offshore Pacific Earthquake (Great East Japan Earthquake), FDMA, viewed < http://www.fdma.go.jp/bn/higaihou/pdf/jishin/157.pdf>.

Fisker-Nielsen, AM 2012, 'Grassroot Responses to the Tohoku Earthquake of 11 March 2011: Overcoming the Dichotomy Between Victim and Helper', Anthropology Today, vol. 28, no. 3, pp. 16-20.

Fitzpatrick, KM \& Spialek, ML 2020, Hurricane Harvey's Aftermath: Place, Race, and Inequality in Disaster Recovery, 1st edition edn, NYU Press; .

Flanagan, BE, Gregory, EW, Hallisey, EJ, Heitgerd, JL \& Lewis, B 2011, 'A Social Vulnerability Index for Disaster Management', Journal of Homeland Security and Emergency Management, vol. 8, no. 1.

Furukawa, S 2002, 'An Institutional Framework for Japanese Crisis Management', Journal of Contingencies and Crisis Management, vol. 8, no. 1, pp. 3-14.

Fussell, E, Delp, L, Riley, K, Chávez, S \& Valenzuela, AJ 2018, 'Implications of Social and Legal Status on Immigrants' Health in Disaster Zones', American Journal of Public Health, vol. 108, no. 12, pp. 1617-1620. 
Galindo, G \& Batta, R 2013, 'Review of Recent Developments in OR/MS Research in Disaster Operations Management', European Journal of Operational Research, vol. 230, no. 2, pp. 201-211.

Gokon, H \& Koshimura, S 2012, 'Mapping of Building Damage of The 2011 Tohoku Earthquake Tsunami in Miyagi Prefecture', Coastal Engineering Journal, vol. 54, no. 1, pp. 1250006-1250001-1250012.

Goulding, C, Kelemen, M., \& Kiyomiya, T 2018, 'Community based response to the Japanese tsunami: A bottom-up approach', European Journal of Operational Research, vol. no. 268, p. 3.

Healy, A \& Malhotra, N 2009, 'Myopic Voters and Natural Disaster Policy', American Political Science Review, vol. 103, no. 3, pp. 387-406.

JICA, JICA 2017, JICA's Cooperation for Disaster Risk Reduction, JICA, Japan, <https://www.jica.go.jp>.

Jones, M \& Ward, K 2007, 'Neo-Liberalism, Crisis and the City: The Political Economy of New Labour's Urban Policy', in C Johnstone, Whitehead, M. (ed.), New Horizons in British Urban Policy: Perspectives on New Labour's Urban Renaissance, Ashgate Publishing Limited, Aldershot, UK, pp. 143-155.

Juncos, AE \& Joseph, J 2020, 'Resilient Peace: Exploring the Theory and Practice of Resilience in Peacebuilding Interventions ', Journal of Intervention and Statebuilding, vol. 14, no. 3, pp. 289-302.

Kaneko, Y 2013, 'Law and Community in Disaster Recovery: Lessons from the 2011 Great East Japan Earthquake on the Outcomes of Civil Rights', प्वस्पव, vol. 21, no. 1, pp. 23-52.

Kloos, B, Hill, J, Thomas, E, Wandersman, A \& Elias, MJ 2012, Cengage Advantage; Community Psychology: Linking Individuals and Communities, 3rd edn, Wadsworth Publishing, Belmont, CA, USA.

Kodama, S 2015, 'Tsunami-Tendenko and Morality in Disasters', Journal of Medical Ethics, vol. 41, no. 5.

Koshimura, S \& Shuto, N 2015, 'Response to the 2011 Great East Japan Earthquake and Tsunami disaster', Philosophical Transactions of the Royal Society A: Mathematical, Physical and Engineering Sciences, vol. 373, no. 2053, p. 20140373.

Mannakkara, S, Wilkinson, S \& Potangaroa, R 2019, Resilient Post Disaster Recovery through Building Back Better, Routledge.

Manzo, LC \& Perkins, DD 2006, 'Finding Common Ground: The Importance of Place attachment to Community Participation and Planning', CPL Bibliography, vol. 20, no. 4, pp. 335-350.

Maskrey, A 1989, Disaster Mitigation: A Community-Based Approach, Oxford, Oxfam.

Matsuoka, Y, Joerin, J, Shaw, R \& Takeuchi, Y 2012, Partnership between City Government and Community-Based Disaster Prevention Organizations in Kobe, Japan in Community Based Disaster Risk Reduction, Emerald, Bingley, UK. 
Mavrodieva, AV, Daramita, RIF, Arsono, AY, Yawen, L \& Shaw, R 2019, 'Role of civil society in sustainable urban renewal (Machizukuri) after the Kobe Earthquake', Sustainability, vol. 11, no. 2, pp. 335-349.

McCloskey, DN 2011, 'Never Waste a Good Crisis', in RJ Samuels (ed.), 3.11 Disaster and Change in Japan, Cornell University Press, Ithaca and London, pp. 24-11.

McConnell, A \& Strak, A 2002, 'Foot-and-Mouth 2001: The Politics of Crisis Management', Parliamentary Affairs, vol. 55, no. 1, pp. 664-681.

McMillan, DW \& Chavis, DM 1986, 'Sense of Community: A Definition and Theory', Journal of Community Psychology, vol. 14, no. 1, pp. 6-23.

Menoni, S, Molinari, D, Parker, D, Ballio, F \& Tapsell, S 2012, 'Assessing Multifaceted Vulnerability and Resilience in Order to Design Risk-Mitigation Strategies', Natural hazards, vol. 64, no. 3, pp. $2057-2082$.

Mills, D 2004, 'Defining Community: A Critical Review of "Community” in Family and Community History', Family \& Community History, vol. 7, no. 1, pp. 5-12.

Mullins, MR \& Nakano, K 2016, 'Disasters and Social Crisis in Contemporary Japan: Political, Religious and Sociocultural Responses', in MRMK Nakano (ed.), Palgrave Macmillan, New York, NY, pp. $288-308$.

Muramatsu, N \& Akiyama, H 2011, 'Japan: Super-Aging Society Preparing for the Future', The Gerontologist, vol. 51, no. 4, pp. 425-432.

Nagamatsu, S 2018, 'Building Back a Better Tohoku After the March 2011 Tsunami: Contradicting Evidence', in The 2011 Japan Earthquake and Tsunami: Reconstruction and Restoration, Springer, pp. 3754.

Nakano, K 2016, The Right-Wing Media and the Rise of Illiberal Politics in Japan, In Press Freedom in Contemporary Japan, Routledge.

National Police Agency of Japan, N 2011, Japan: Damage Situation and Police Countermeasures associated with 2011Tohoku district - off the Pacific Ocean Earthquake, March 20, 2011 at 3:00pm, viewed 14/02/2020, <https://reliefweb.int/report/japan/japan-damage-situation-and-policecountermeasures-associated-2011tohoku-district>.

Nobushige, T 2011, 3.11 Disaster, Ministry of Defense Policy Bureau Chief, Tokyo, Japan.

OECD, OfEC-oaD 2015, The Changing Face of Strategic Crisis Management, O Publishing, France, Paris.

Okada, N, Fang, L \& Kilgour, DM 2013, 'Community-based Decision Making in Japan', Group Decisions Negotiation, vol. 22, no. 1, pp. 45-52.

Oliver-Smith, A 2011, Defying Displacement: Grassroots Resistance and the Critique of Development, University of Texas Press, USA. 
Oliver, AJ \& Reeves, A 2015, 'The Politics of Disaster Relief', in RASSMKM Buchmann (ed.), Emerging Trends in the Social and Behavioral Sciences: An Interdisciplinary, Searchable, and Linkable Resource, John Wiley \& Sons, pp. 1-8.

Payne, BA, Becker, JS, Kaiser, LH \& Taylor-Offord, S 2020, 'They're going to arrive, ready or not': Hill-based residents capacity to support the evacuated after earthquake and tsunami', Australian Journal of Emergency Management, vol. 35, no. 4, pp. 35-41.

Pelling, M \& Dill, K 2010, 'Disaster Politics: Tipping points for change in the adaptation of sociopolitical regimes', Progress in Human Geography, vol. 34, no. 1, pp. 21-37.

Robertson, T, Docherty, PM, F., Ruck, A \& Engstrom, S 2021, 'Theory and practice of building community resilience to extreme events', International Journal of Disaster Risk Reduction, vol. 59, no. 1, pp. 1-7.

Samuels, RJ 2013, 3.11 Disaster and Change in Japan, Cornell University Press, Ithaca and London.

Shah, R, Paulson, J \& Couch, D 2020, 'The Rise of Resilience in Education in Emergencies', Journal of Intervention and Statebuilding, vol. 14, no. 3, pp. 303-326.

Shaw, R 2014, Kobe Earthquake: Turning Point of Community-Based Risk Reduction in Japan, Community Practices for Disaster Risk Reduction in Japan, Springer, Tokyo, Japan.

Sorensen, A \& Funck, C 2009, Living Cities in Japan: Citizens' Movements, Machizukuri and Local Environments, The Nissan Institute/Routledge Japanese Studies, New York, NY.

Suter, R 2016, 'Beyond Kizuna: Responses to Disaster in the Works of Murakami Haruki', in MRMK Nakano (ed.), Disasters and Social Crisis in Contemporary Japan: Political, Religious and Sociocultural Responses, Palgrave Macmillan, New York, NY, pp. 288-308.

Suzuki, I \& Kaneko, Y 2013, Japan's Disaster Governance: How was the 3.11 Crisis Managed?, Springer, New York, USA.

Suzuki, I \& Kaneko, Y 2016, 'Fukushima Nuclear Disaster and Ensuring Necessary Government Crisis and Risk Communication', in Global Cases in Best and Worst Practice in Crisis and Emergency Management, Routledge, The Sasakawa Peace Foundation.

Tanaka, S 2008, Local Disaster Management and Hazard Mapping.

Thiri, MAN 2017, 'Vulnerability and Environmental Migration: The Case of Miyagi Prefecture after the Great East Japan Earthquake', International Journal of Disaster Risk Reduction, vol. 25, no. 1, pp. 212226.

Trumble, R 2019, 'A Proposal for Unpacking the Politics of Knowledge Production in Disaster Reduction Education', Geography Compass, vol. 13, no. 1, p. e12411. 
UNISDR 2016, The United Nation Office for International Disaster Risk Reduction, viewed 22/11/2016, $<$ http://www.unisdr.org/who-we-are>.

Van Wassenhove, LN 2006, 'Humanitarian Aid Logistics: Supply Chain Management in High Gear', Journal of the Operational Research Society, vol. 57, no. 5, pp. 475-489.

WHO, WHO 2012, The Great East Japan Earthquake: A story of a Devastating Natural Disaster, A Tale of Human Compassion.

Wisner, B, Blaikie, T, Cannon, T \& Davis, I 2004, At Risk, Routledge, USA.

Zhou, L, Perera, S, Jayawickrama, J \& Adeniyi, 0 2017, 'The Implication of Hyogo Framework for Action for Disaster Resilience Education', Procedia Economics and Finance, vol. 18, no. 1, pp. 576-583.

\section{Figures}

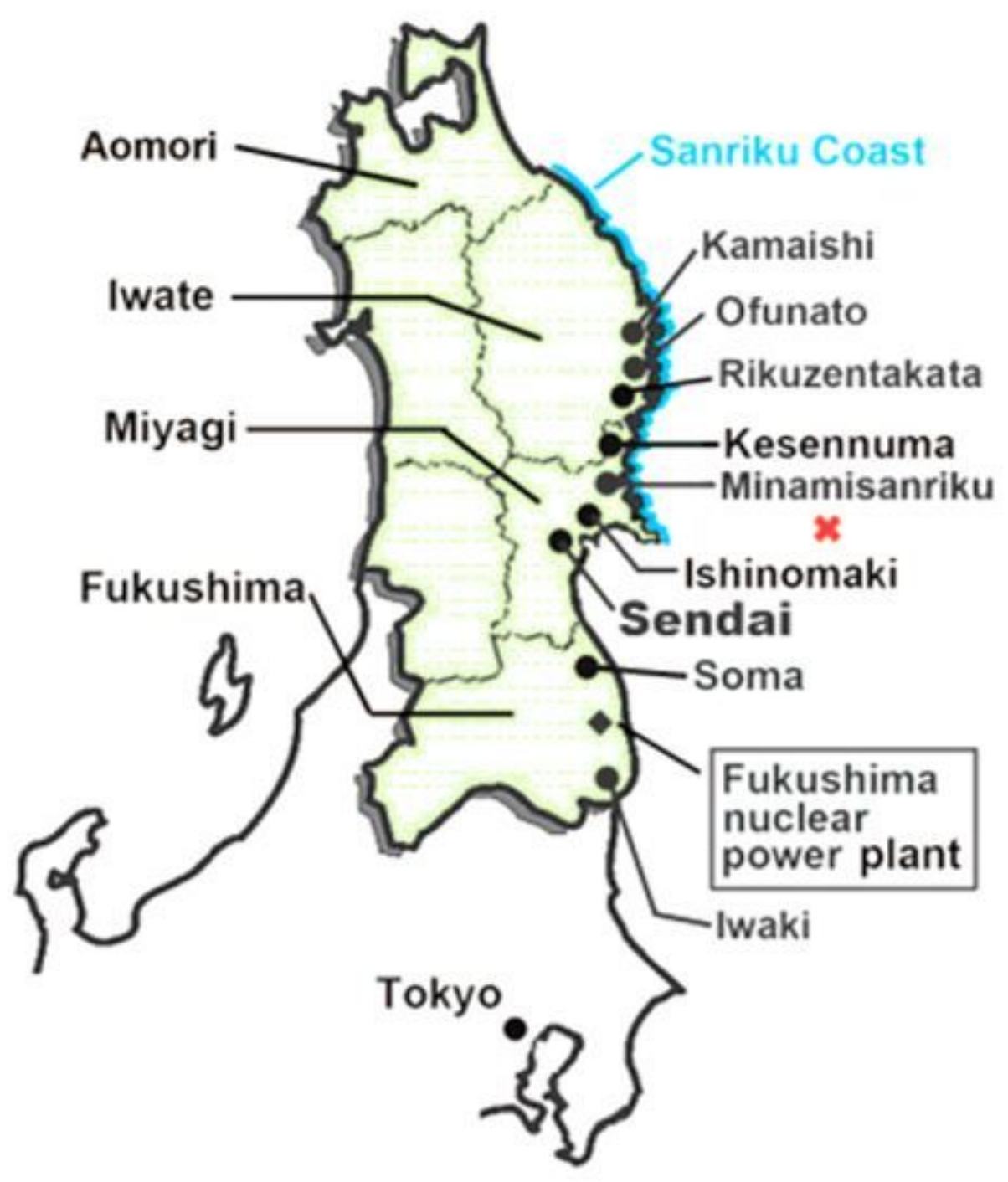




\section{Figure 1}

The impact of the GEJET - Sanriku Region, Iwate and Miyagi Prefecture - the closest prefecture to the epicentre

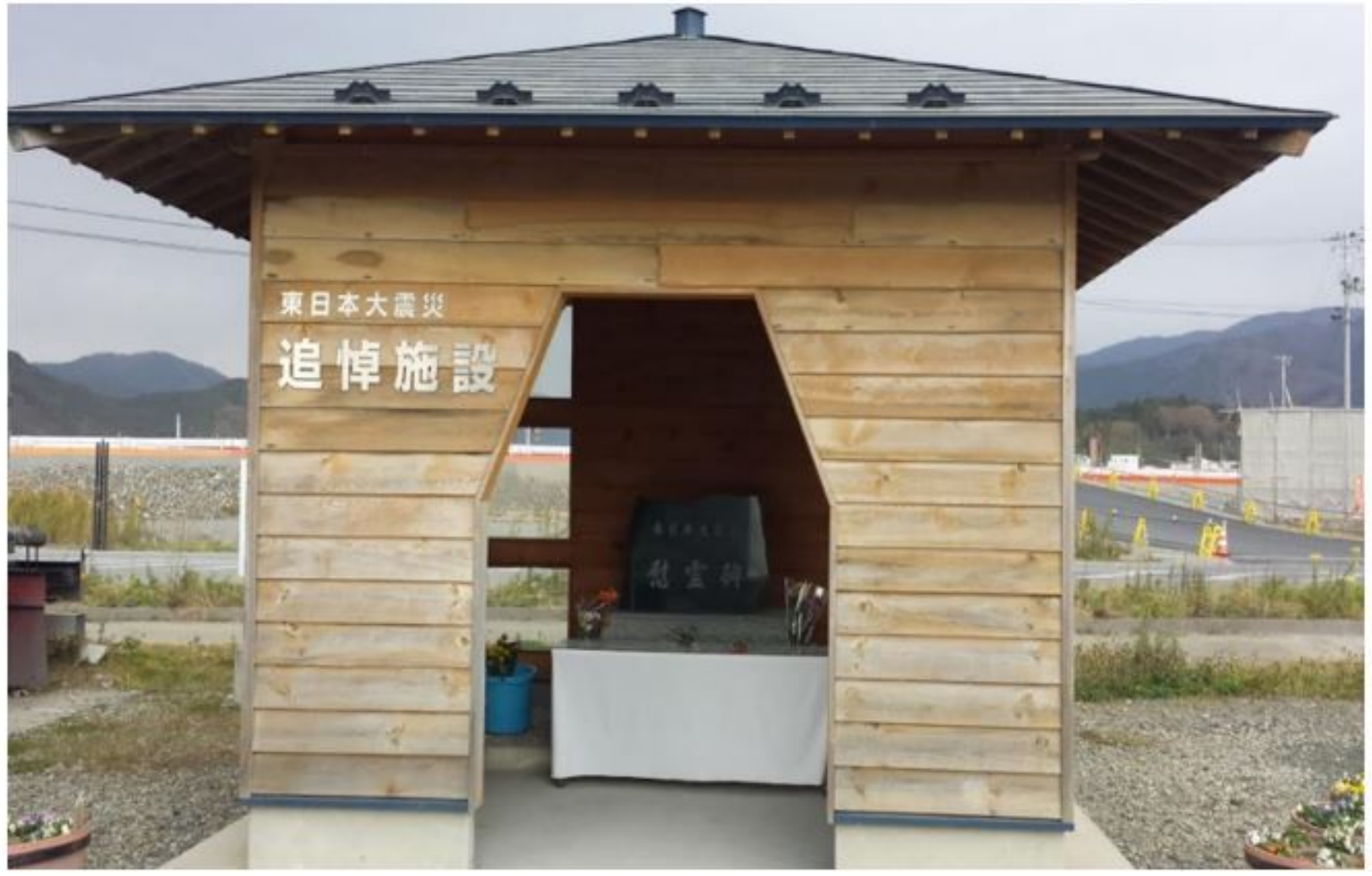

\section{Figure 2}

Memorial building for the Great East Japan Disaster and memorial stone inside of the building - Source: the author 


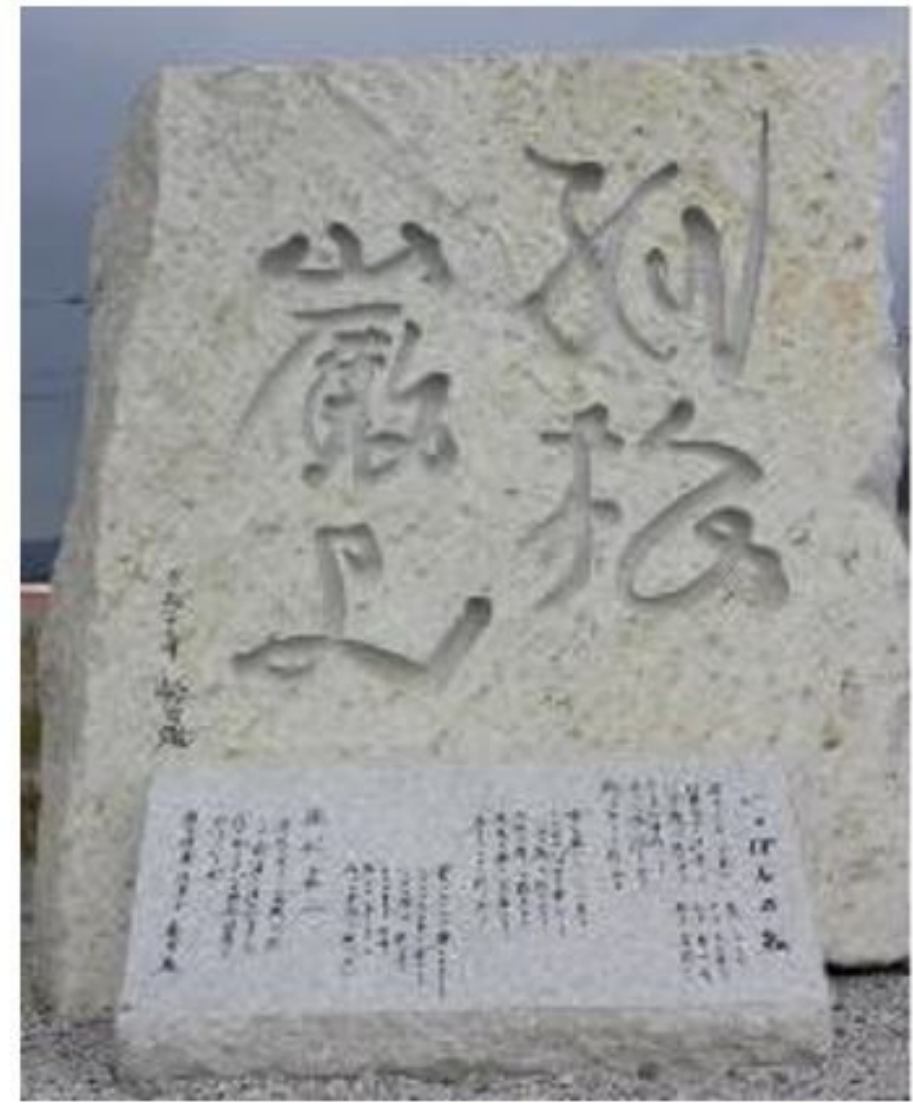

Figure 3

Calligraphy on the stone: "One pine tree" - describing living strongly despite the difficulties - Source: the author 


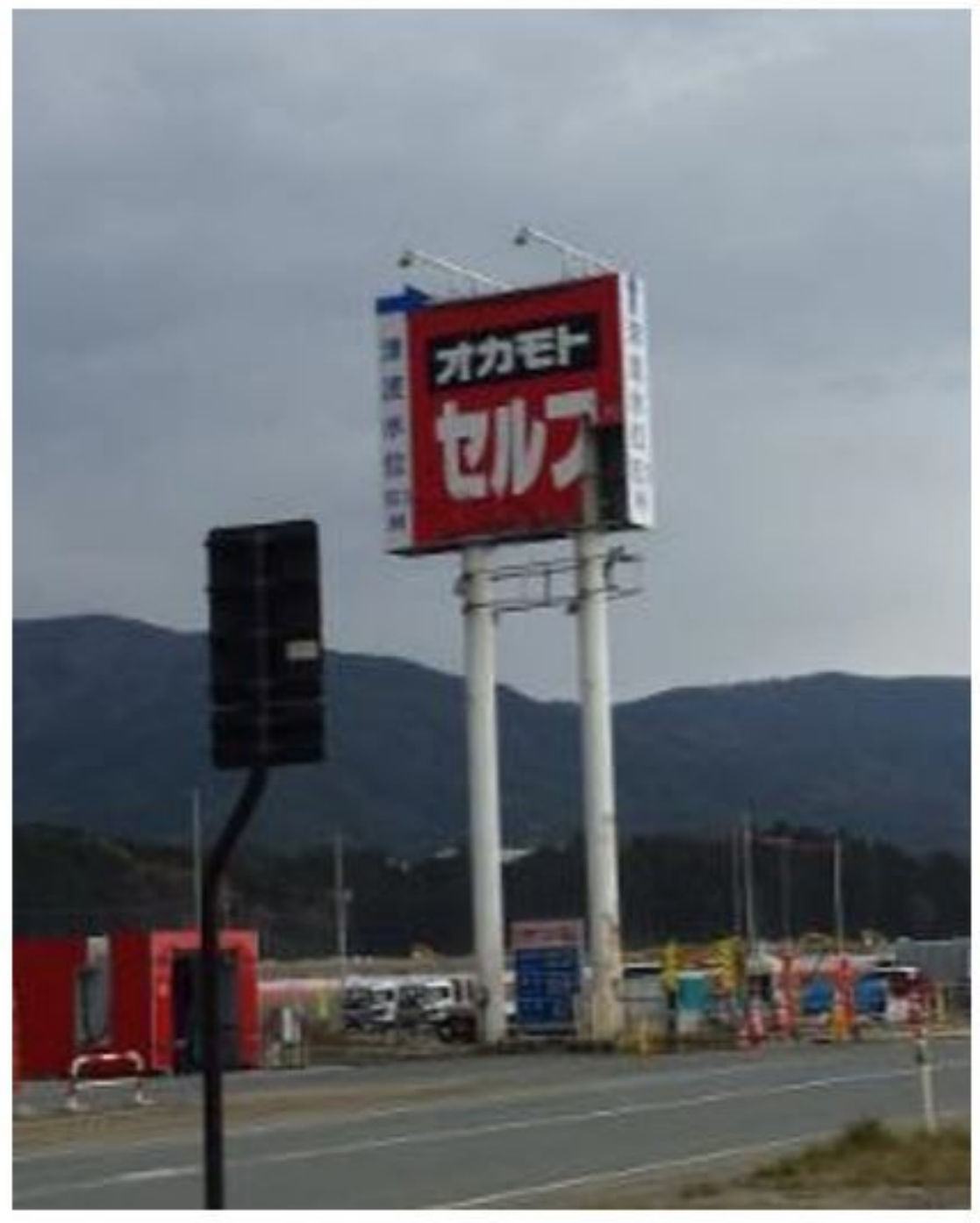

Figure 4

Self-service petrol station sign showing the highest level of the Tsunami (15.1M) - Source: the author 


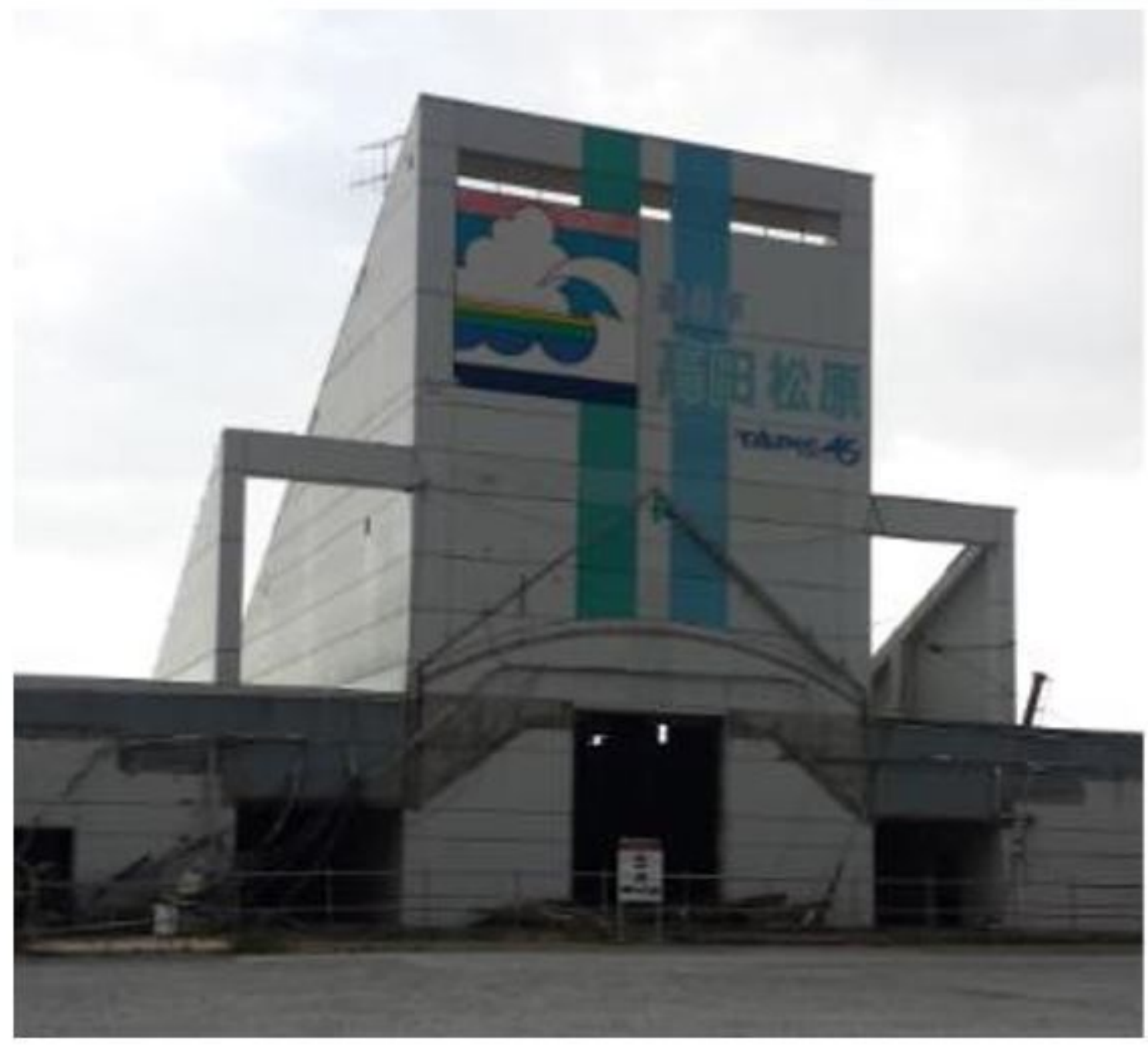

Figure 5

Service station: Tsunami resistant building - source: the author 


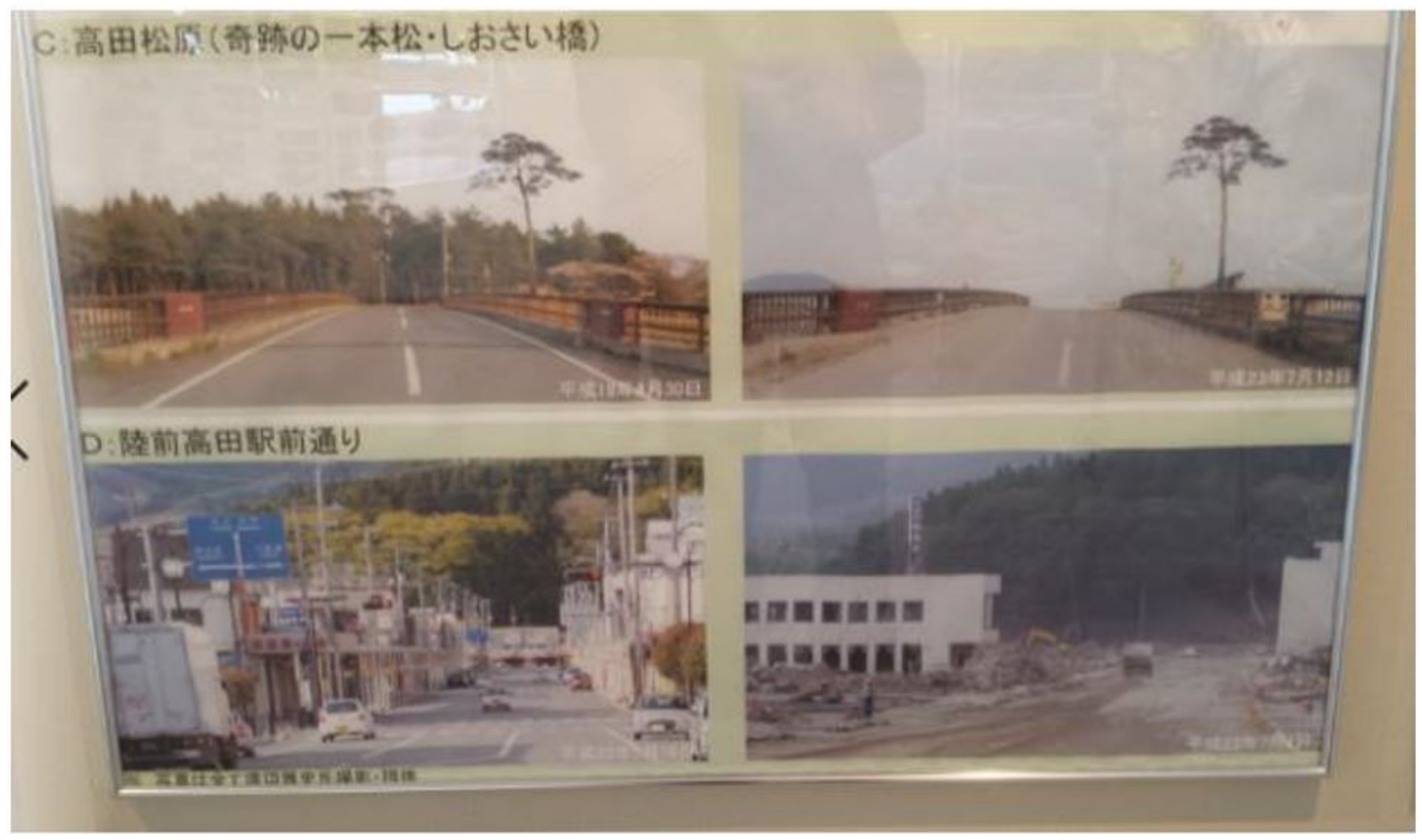

\section{Figure 6}

The Miracle Pine Tree ( iconic symbol of hope in the Japanese tsunami city. The tree was one of 70,000 in a forest that had protected the city of Rikuzentakata from ocean winds for more than 300 years. These are images of before and after the tsunami. Source: the author. 


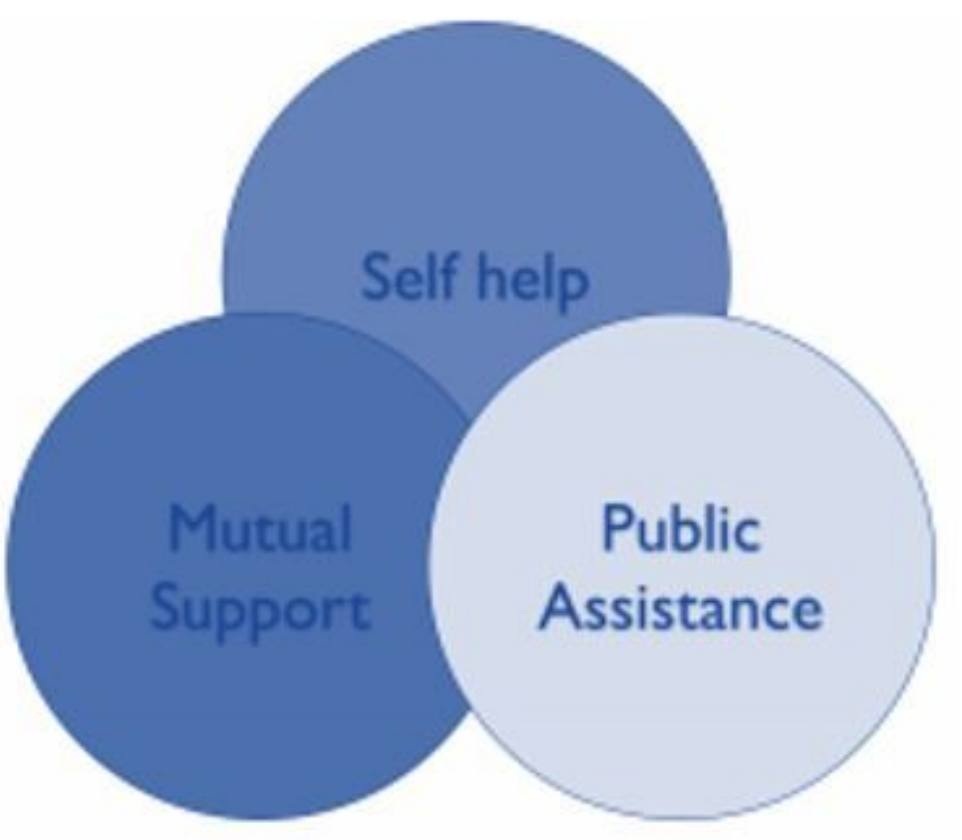

Figure 7

Three Components of Japan's Disaster Management System (Source: Tanaka 2008) 
Outline of the Disaster Management System in Japan

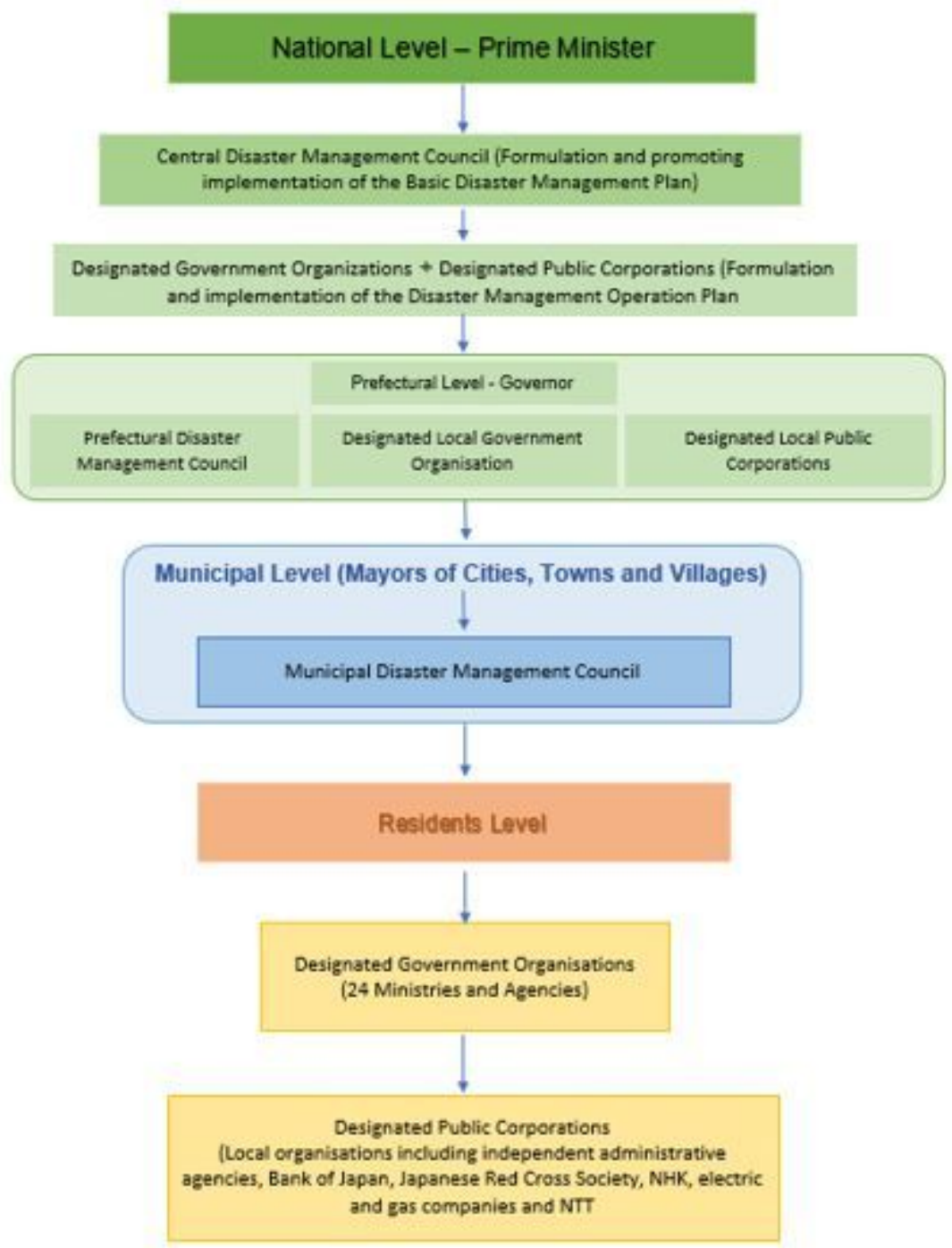

Figure 8

Disaster Management System in Japan (Source: adapted from Disaster Management System 2011, The Cabinet Office) - the author 